NBSIR 83-2642

Fire Hazard Evaluation of Shipboard Hull Insulation and Documentation of A Quarter-Scale Room Fire Test Protocol

U.S. DEPARTMENT OF COMMERCE

National Bureau of Standards

National Engineering Laboratory

Center for Fire Research

Washington, DC 20234

August 1983

Prepared for:

Ship Damage Prevention and Control

Naval Sea Systems Command

QC Department of the Navy Washington, DC 20362 

FIRE HAZARD EVALUATION OF SHIPBOARD HULL INSULATION AND DOCUMENTATION OF A QUARTER-SCALE ROOM FIRE TEST PROTOCOL

B. T. Lee

U.S. DEPARTMENT OF COMMERCE

National Bureau of Standards

National Engineering Laboratory

Center for Fire Research

Washington, DC 20234

August 1983

Prepared for:

Ship Damage Prevention and Control

Naval Sea Systems Command

Department of the Navy

Washington, DC 20362

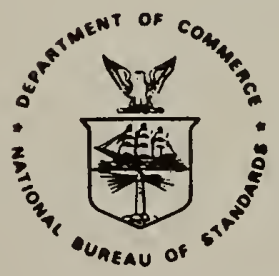

U.S. DEPARTMENT OF COMMERCE, Malcolm Baldrige, Secretary NATIONAL BUREAU OF STANDARDS, Ernest Ambler, Director 

TABLE OF CONTENTS

$\underline{\text { Page }}$

LIST OF FIGURES . . . . . . . . . . . . . . . . . . . . iv

LIST OF TABLES . . . . . . . . . . . . . . . . . . . . v v

ABSTRACT •. . . . . . . . . . . . . . . . . . . . 1

1. INTRODUCTION . . . . . . . . . . . . . . . . . . . 1

2. FACILITIES AND EXPERIMENTAL TESTS . . . . . . . . . . . . . 2

2.1 Facilities and Instrumentation .............. 2

2.2 Calibration of Exhaust Collector Hoods for

Heat Release Rate Measurement . . . . . . . . . 4

2.3 Test Materials .................. 4

2.4 Experimental Tests . . . . . . . . . . . . . . 5

2.4.1 Room and Laboratory Fire Test Procedures . . . . . 5

2.4.2 Room and Laboratory Fire Tests . . . . . . . . 5

3. RESULTS AND DISCUSSION . . . . . . . . . . . . . . . 7

3.1 Fire Performance Evaluation of Materials . . . . . . . 7

3.1.1 Quarter-Scale Room Fire Test . . . . . . . . . 7

3.1.2 Laboratory Fire Tests . . . . . . . . . . 7

3. 2 Full-Scale Tests and Comparisons with

Quarter-Scale Tests ................. 9

3.3 Effect of Paint on Fire Performance of

Hull Insulation . . . . . . . . . . . . . . . 11

3.4 Test Protocol for Quarter-Scale Test . . . . . . . . 12

4. CONCLUDING REMARKS . . . . . . . . . . . . . . . . . . 14

5. ACKNOWLEDGEMENTS . . . . . . . . . . . . . . . . 15

6. REFERENCES . . . . . . . . . . . . . . . . 15

APPENDIX A. Test Protocol on the Determination of the

Flashover Potential of Shipboard Hull Insulation

Using a Quarter-Scale Room Fire test . . . . . . . 17 


\section{LIST OF FIGURES}

$\underline{\text { Page }}$

Figure 1. Layout and instrumentation for quarter-scale test . . . . 19

Figure 2. Quarter-scale and full-scale room fire tests . . . . . . 20

Figure 3. Layout and instrumentation for full-scale test . . . . . . 21

Figure 4. Air temperatures near center of ceiling for full-

scale test 2 and corresponding quarter-scale tests . . . . 22

Figure 5. Air temperatures near center of ceiling for fullscale test 3 and corresponding quarter-scale tests . . . . 23

Figure 6. Air temperatures near center of ceiling for fullscale test 4 and corresponding quarter-scale tests . . . . 24

Figure 7. Air temperatures near top of doorway for fullscale test 2 and corresponding quarter-scale tests . . . . 25

Figure 8. Air temperatures near top of doorway for fullscale test 3 and corresponding quarter-scale tests . . . . 26

Figure 9. Air temperatures near top of doorway for fullscale test 4 and corresponding quarter-scale tests .....

Figure 10. Heat flux on floor for full-scale test 2 and corresponding quarter-scale tests ............

Figure 11. Heat flux on floor for full-scale test 3 and corresponding quarter-scale tests ............

Figure 12. Heat flux on floor for full-scale test 4 and corresponding quarter-scale tests . . . . . . . . 30

Figure 13. Mass flow rate of carbon monoxide for fullscale tests 2 and 3 and their corresponding quarter-scale tests . . . . . . . . . . . . .

Figure 14. Mass flow rate of carbon monoxide for fullscale test 4 and corresponding quarter-scale tests ......................

Figure 15. Rate of heat release from full-scale tests 2 and 3 and their corresponding quarter-scale tests . . . . . . . . . . . . . . . . .

Figure 16. Rate of heat release from full-scale test 4 and corresponding quarter-scale tests 
Table 1. Materials used in the room and laboratory

Table 2. Comparison of results from full-scale room

fire tests and their counterpart quarterscale tests . . . . . . . . . . . . 37

Table 3A. Summary of quarter-scale test results . . . . . . . 38

Table 3B. Summary of quarter-scale test results . . . . . . . 39

Table 4. Ignitability, flame spread, and smoke characteristics of materials used in room fire tests.................. . . 40

Table 5. Heat release rate and potential heat of materials used in room fire tests . . . . . . . . .

Table 6. Comparison of peak air temperatures at several elevations near the ceiling and top of the doorway ................ 



\title{
FIRE HAZARD EVALUATION OF SHIPBOARD HULL INSULATION AND DOCUMENTATION OF A QUARTER-SCALE ROOM FIRE TEST PROTOCOL
}

\author{
B.T. Lee
}

\section{Abstract}

A variety of shipboard hull insulations including damping and acoustical materials, painted and unpainted, were evaluated for their flashover potential using a quarter-scale room fire test developed by the Center for Fire Research at the National Bureau of Standards. Three painted insulations were also evaluated in full-scale room fire tests. Comparison of full-scale and quarter-scale fire behavior again demonstrated that the quarter-scale test can predict full-scale room fire buildup. It was found that decorative paints, including the Navy's chlorinated alkyd formulation, could seriously compromise the fire safety of otherwise low fire risk insulations. A recommended test protocol was developed for determining the flashover potential of hull insulation using the quarter-scale room fire test.

Keywords: Flammability; flashover; heat release rate; insulation; interior finishes; paints; room fires; ships; small-scale fire tests.

\section{INTRODUCTION}

Recent research $[1]^{1}$ has demonstrated that fire hazards associated with the use of certain synthetic foam materials, in the insulation of the interior of submarines, can be satisfactorily assessed only with room fire testing and not with small scale laboratory fire tests which are employed for measuring fire properties of materials. As part of the same study, a one-quarter size room fire test was developed for screening these kinds of materials with the same reliability as full-scale testing but much more economically. This quarter-scale test was a less severe fire test than its counterpart full-scale test, but did give the same order of rating, based on the degree of room fire buildup achieved, as the full-scale test for the foam materials evaluated. The quarter-scale test has also been successful in simulating full-scale room fire tests of some interior finish material not associated with shipboard use [2]. Nevertheless, there is a need to evaluate the quarter-scale room fire test with a wider range of materials intended for use on shipboard to assess its strengths and limitations. Additionally, a standardized

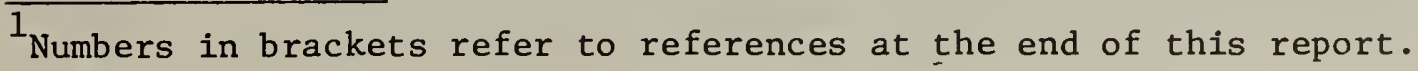


quarter-scale test room and test procedure must be established such that the testing can be repeated and the capabilities of the test verified by others. Concurrent with these goals is the present need to use the test as a tool for screening shipboard finish materials. Thus, the present work has the following objectives:

1. to evaluate the potential fire hazards of shipboard hull insulations including damping and acoustical materials, painted and unpainted;

2. to further evaluate the effectiveness of the one-quarter size room test and the suitability of laboratory fire tests for assessing the fire performance of these materials; and

3. to document a test protocol such that the Navy and other test facilities may independently conduct fire test evaluations on such materials.

This report discusses the quarter-scale room fire tests of a variety of shipboard hull insulations and the degree of agreement achieved with fuil-scale room test results for three painted insulations. Also included in this report are laboratory fire test data obtained on these insulation materials using: an ease of ignition test [3], the ASTM E 162 [4] and E 84 [5] tests for measuring surface flammability, a rate of heat release calorimeter test [6], and the potential heat [7] and smoke generation [8] tests. These laboratory fire test results are compared with the performance of the materials as observed in the room fire tests.

In this study, the basic criterion adopted for limiting fire growth was that the painted and unpainted insulations, when subjected to a moderately large fire exposure, would not lead to flashover of the test room during an exposure period of $1800 \mathrm{~s}$. Flashover is defined here as that condition where the thermal radiation level becomes high enough to spontaneously ignite light combustible materials (such as newspaper) located in the lower half of the room. Flashover is frequently preceded by flameover, a condition where flames emerge from the room across the top of the doorway.

\section{FACILITIES AND EXPERIMENTAL TESTS}

\subsection{Facilities and Instrumentation}

The quarter-scale room enclosure measured $0.76 \mathrm{~m} \times 0.76 \mathrm{~m} \times 0.61 \mathrm{~m}$ high and scaled a room measuring $3.05 \mathrm{~m} \times 3.05 \mathrm{~m} \times 2.44 \mathrm{~m}$ high. This enclosure consisted of a $6.4 \mathrm{~mm}$ thick aluminum alloy shell which was positioned over a $6.4 \mathrm{~mm}$ steel floor. The model enclosure had a doorway opening of $0.49 \mathrm{~m} \times 0.43 \mathrm{~m}$ high based on scaling principles and empirical adjustments developed earlier [1]. 
A $0.61 \mathrm{~m} \times 0.91 \mathrm{~m}$ hood having an exhaust capability of $0.18 \mathrm{~m}^{3} / \mathrm{s}$ was located above the door opening of the quarter-scale enclosure to collect the exhaust from the fire. A $1.22 \mathrm{~m}$ long, $0.15 \mathrm{~m}$ diameter vertical stack having an inlet diameter of $83 \mathrm{~mm}$ was connected to the hood. The smaller diameter opening was used to increase turbulent mixing of the exhaust. Smoke attenuation of a light beam was measured at $0.55 \mathrm{~m}$ above the inlet. Temperature, air velocity, and oxygen, carbon dioxide, and carbon monoxide concentrations in the stack were measured at a position $1.0 \mathrm{~m}$ above the inlet, where the exhaust across a cross-section of the stack was found to be well mixed. From these measurements, the rate of heat release, the mass flow of carbon monoxide, and the optical density of smoke generated from the fire were determined.

Figure 1 indicates the type and location of instrumentation employed in the quarter-scale room fire tests. Figure 2 shows the test arrangement. The stack temperature was measured with a chromel-alumel thermocouple made from Brown and Sharpe 24 gauge $(0.51 \mathrm{~mm})$ diameter wire. Air velocity in the stack was monitored with a pitot tube. Oxygen concentration was sensed directly with a paramagnetic analyzer. Carbon monoxide and carbon dioxide were monitored with non-dispersive infrared analyzers. In addition, thermocouples fabricated from $0.05 \mathrm{~mm}$ chromel and alumel wires were located along the vertical centerline of the doorway opening at distances of $25,51,102,203,254$ and $356 \mathrm{~mm}$ below the top of the doorway. Small junction thermocouples made from $0.05 \mathrm{~mm}$ wire were chosen to minimize thermal radiation errors in the measurement of air temperatures in the room fires [9]. Identical thermocouples were located at distances of $25,51,102,203,305,457$ and $610 \mathrm{~mm}$ below the center of the ceiling. These thermocouple trees were used to ascertain the most suitable heights in the doorway and inside the room for measuring the peak air temperatures. The thermal flux at the floor, measured with water-cooled, total heat flux gauges of the Gardon type, was also taken to characterize the room environment.

In previous work [1], a full-scale fire test room was assumed to measure $3.05 \mathrm{~m} \times 3.05 \mathrm{~m} \times 2.44 \mathrm{~m}$ high with a $762 \mathrm{~mm} \times 2032 \mathrm{~mm}$ high opening at the middle of one wall. However, based on recent recommendations by the ASTM E 5 committee on fire standards, a standard fullscale fire test room shall have dimensions of $2.44 \mathrm{~m} \times 3.66 \mathrm{~m} \times 2.44 \mathrm{~m}$ high with the same size opening at the middle of the $2.44 \mathrm{~m}$ wide wall. It is expected that this change should have little effect on the fire development as the floor area is decreased by only 4 percent and the air flow into the room depends mainly on the doorway opening which remains unchanged. All four walls and the ceiling were fabricated from $6.4 \mathrm{~mm}$ thick aluminum alloy plate or sheet mounted over 51 x $102 \mathrm{~mm}$ steel spacer studs $0.41 \mathrm{~m}$ apart. The floor consisted of $3.2 \mathrm{~mm}$ thick aluminum sheets over a concrete slab. The room was constructed within a large building, so that the effects of temperature extremes and wind were eliminated. The test room was located adjacent to a large $3.66 \mathrm{~m} \times 4.88 \mathrm{~m}$ exhaust collector hood having an exhaust capacity of about $3.0 \mathrm{~m} / \mathrm{s}$. 
The stack to the hood and the room were instrumented similarly to that used with the quarter-scale test. The full-scale test arrangement and instrumentation layout are given in figures 2 and 3.

\subsection{Calibration of Exhaust Collector Hoods for Heat Release Rate Measurements}

The exhaust collection stack for the quarter-scale test was calibrated for measurement of heat release rate using the quarter-scale methane burner, described in section 2.4.1, positioned directly under the hood as well as inside the room. The same burner was also used as the ignition source for the room fire tests. The burner operated at a heat release rate of $16.5 \mathrm{~kW}$ based on a flow rate of $490 \mathrm{ml} / \mathrm{s}$ of methane to the burner. The rate of heat release from the burner can also be determined from the measurement of the volume flow rate and the oxygen depletion of the air passing through the stack [10]. The calculated value based on this latter technique was $17.1 \mathrm{~kW}$, or 4 percent larger than the actual value based on the methane flow rate, for the burner located directly under the hood. When the burner having the same methane flow rate was positioned at the center of the floor, the calculated value was $15.8 \mathrm{~kW}$, or 4 percent smaller than the actual rate. The \pm 4 percent accuracy is well within an estimated \pm 10 percent experimentāl uncertainty. Thus, the measurement of heat rélease rate with the hood system was found to be adequate, and no calibration factor was needed. For the full-scale exhaust system, the stack was calibrated in another study [9]. The study indicated that the flow in the full-scale stack was highly non-uniform and the heat release rate measurements had to be multiplied by 0.77 to give the actual values. That calibration was used for the calculations of heat release rate in this report.

\subsection{Test Materials}

The materials selected by the Navy and used in the room and laboratory fire tests are described in table 1. The acoustic materials conforming to specification MIL-I-22023 are general purpose insulations. Materials TS-GM and M-AL are currently in use, while the M, TS-MG, and TS-GMG are candidate materials. The $W-1$ and $W-2$ materials conform to MIL-A-23054 and are used primarily in the ventilation equipment spaces. of the five insulations listed under the heading of hull insulation, material $G$ is mainly for surface ship application. The B2II and cork are utilized on submarines. The hydrophilic polyurethane $\mathrm{H}$ and the silicone rubber SR are candidate materials. The six damping materials are used more on board submarines than on surface ships. The adhesives and coatings listed are presently used shipboard materials with the exception of the 0-1001, which is a candidate coating. On board ship, glass cloth conforming to MIL-C-20079 is used to cover the joints between insulation sections for all of the acoustic materials and the hull insulation $G$. The other insulations and the damping materials do not have taped joints. 


\subsection{Experimental Tests}

\subsubsection{Room and Laboratory Fire Test Procedures}

In both quarter-scale and full-scale room fire tests, the test material fully covered the walls and ceiling. As much as possible, the materials were mounted in the same manner as on board ship. For the quarter-scale room test, a $76 \mathrm{~mm} \times 76 \mathrm{~mm}$ diffusion flame gas burner, with its horizontal surface located $76 \mathrm{~mm}$ off the floor, was positioned snugly against one back corner of the test room such that there was no air gap between the burner and the two walls. This burner served as the ignition source and was left on throughout the test period. A flow rate of $150 \mathrm{ml} / \mathrm{s}(0.32 \mathrm{CFM})$ of methane was metered to the burner to produce a constant heat input of $5.6 \mathrm{~kW}$. This represented $1 / 16$ of the rate for a full-scale room burner, based on previously developed scaling principles [1]. The test duration was chosen to be $1800 \mathrm{~s}$ except when flashover occurred earlier or when the fire environment posed a danger to the structural integrity of the quarter-scale test facility, at which time the test was terminated. The test was also stopped after $900 \mathrm{~s}$ for materials that did not appear to burn significantly by that time. In the full-scale room test, $2.4 \mathrm{l} / \mathrm{s}$ ( 5.1 CFM) of methane corresponding to 90 $\mathrm{kW}$ was metered to a $305 \mathrm{~mm} \times 305 \mathrm{~mm} \times 305 \mathrm{~mm}$ high diffusion flame burner positioned snugly against a rear corner of the room. As in the quarterscale test, the burner was left on over the duration of the test. The full-scale facility was intended to withstand severe fire exposures over a long period of time. Consequently, all full-scale tests were conducted over the $1800 \mathrm{~s}$ duration, regardless of the fire environment. Measurements in the full-scale and quarter-scale room tests, using the instrumentation described in section 2.1, were recorded continuously. In addition, four pieces of crumpled newspaper on the floor served as visual indicators of flashover.

Only currently used laboratory fire tests with published test procedures were used in this study. Consequently, these procedures were employed for the ease of ignition test, the ASTM E 162 and.E 84 tests, the rate of heat release calorimeter, potential heat and smoke generation tests.

\subsubsection{Room and Laboratory Fire Tests}

Twenty-nine quarter-scale tests and three full-scale room fire tests were performed. Nine of the quarter-scale and all of the fullscale tests were on insulations with painted surfaces. Descriptions of the full-scale room tests and their counterpart quarter-scale tests are given in table 2. A listing of all of the tests with the quarter-scale enclosure is given in table 3. For the insulations used in full-scale tests FS-2 and FS-3 and quarter-scale tests 1 to $9,13,5 \mathrm{R}$ and $7 \mathrm{R}$, the test material was impaled on $44.5 \mathrm{~mm}$ long, $2.4 \mathrm{~mm}$ diameter steel studs fastened to the aluminum enclosure at locations $76 \mathrm{~mm}$ away from the corners and edges and at $0.305 \mathrm{~m}$ maximum spacing between studs everywhere 
else. Where the spacing was greater than $0.305 \mathrm{~m}$ but less than $0.61 \mathrm{~m}$, a stud was used midway. Steel clips were then used over the studs to keep the test material in place. All other materials were glued to the enclosure surface using the $\mathrm{M}-30$ adhesive. Test 20 also had the material mechanically attached to the enclosure using screws to prevent separation during the fire exposure.

Data on heat release rate, smoke, and carbon monoxide could not be measured reliably in tests 1 though 10 due to flow measurement difficulties. Of these 10 tests, numbers 5 and 7 were particularly important as they were counterpart tests for two of the three full-scale tests. Consequently, tests $5 R$ and $7 R$, the repeat runs of tests 5 and 7 , were conducted to give data on heat release rate, smoke, and carbon monoxide production and to verify other data from tests 5 and 7 . Tests 14R, 16R, $22 R$, and $27 R$ were also repeat tests of runs $14,16,22$ and 27 and were performed to verify near-flashover situations. Test $21 \mathrm{R}$ was run to verify the finding in test 21 that the B2II insulation did not lead to flashover.

Tests 7, 8, and 9 were stopped at 900 seconds when steady state conditions appeared to have been reached. In test 12 , a section of the test foam insulation on the ceiling directly over the gas burner fell off exposing the aluminum substrate at 780 seconds. The test was terminated at 900 seconds to protect the test enclosure. Test 14 was stopped at $780 \mathrm{~s}$, when flaking from the ceiling surface ignited the newspaper flashover indicators. In test 19, some of the material was hanging off the ceiling and small pieces were dropping off by 1140 seconds. By 1320 seconds, large pieces were falling and burning on the floor; at 1380 seconds, the test was terminated.

A summary of the tests with the ease of ignition apparatus, the ASTM E 162 radiant panel, the ASTM E 84 tunnel, the rate of heat release calorimeter, and the potential heat and smoke generation tests is given in tables 4 and 5 . As surface flammability could be measured with either the E 162 or E 84 test, it was decided to conduct E.162 tests on all the test materials and E 84 tests only on selected acoustical insulations. The E 84 test evaluated materials in an overhead configuration which made it unsuitable for damping insulation, which is used only on vertical surfaces. In addition, the $E 84$ test required a relatively large quantity of material which made test evaluation costly for expensive materials like the damping insulations. As for hull insulations, similar insulations had been evaluated with both tests in an earlier study [1] with the finding that the E 84 test performed no better than the $\mathrm{E} 162$ test in predicting full-scale room fire behavior. On the other hand, acoustical insulations have not been tested with both surface flammability tests. Consequently, the Navy requested that selected acoustical insulations be evaluated with both the E 162 and E 84 tests. 


\section{RESULTS AND DISCUSSION}

\subsection{Fire Performance Evaluation of Materials}

\subsubsection{Quarter-Scale Room Fire Test}

Quarter-scale room test results are given in table 3. Test $5 \mathrm{R}$ with the painted TS-GM, test 10 with the cork, and tests 22,27 and $27 \mathrm{R}$ with the painted B2II produced room flashovers in about $100 \mathrm{~s}$ or earlier. The remaining tests which reached flashover, i.e., test 11 with the SR, tests 16 and $16 \mathrm{R}$ with the BR2-1, and test $14 \mathrm{R}$ with the BR1-1 took over $500 \mathrm{~s}$ to reach flashover. Near flashover situations were achieved in test 5 with the painted TS-GM, test 14 with the BR1-1, and test $22 \mathrm{R}$ with the B2II having two coats of paint. Tests 5,14 , and $22 \mathrm{R}$ reached peak interior air temperatures of $770^{\circ} \mathrm{C}, 650^{\circ} \mathrm{C}$, and $540^{\circ} \mathrm{C}$, respectively, with none of the newspaper flashover indicators igniting in those three tests. Repeat runs of those room fires, tests $5 \mathrm{R}, 14 \mathrm{R}$ and $22 \mathrm{did}$ experience flashover. Tests of two other materials resulted in a moderate rise in air temperature. Test 19 with the $L K-1$ had peak interior and doorway air temperatures of $500^{\circ} \mathrm{C}$ and $340^{\circ} \mathrm{C}$, respectively. Test 21R with the B2II had maximum interior and doorway air temperatures of $440^{\circ} \mathrm{C}$ and $330^{\circ} \mathrm{C}$, respectively. Evidence from previous studies $[1,2]$ has shown that the quarter-scale test is less severe than its counterpart full-scale test. This is further substantiated by the data given in section 3.2, showing that full-scale tests required less time to reach flashover than their corresponding quarter-scale tests. Consequently, there is the possibility that the LK-1 and B2II materials could become borderline fire hazard materials when evaluated with full-scale room fire tests.

Material thickness could have a significant effect on the room fire development. Tests $14,14 \mathrm{R}, 16$, and $16 \mathrm{R}$ with the $9.5 \mathrm{~mm} \mathrm{BR} 1-1$ and the $8.0 \mathrm{~mm}$ BR2-1 damping materials experienced flashover or near flashover. The $15.9 \mathrm{~mm} \mathrm{BR} 1-2$ and $12.7 \mathrm{~mm} \mathrm{BR2-2}$ were similar to the BR1-1 and BR2-1, respectively, except the former two materials were thicker. Fire tests of rooms lined with the BR1-2 and BR2-2 did not approach flashover conditions. All four materials have a high thermal conductivity as heat was readily transferred to the test enclosure when these materials were used. Consequently, the thick materials would reach lower temperatures, because of their greater mass, than the thinner materials for the same quantity of heat absorbed.

\subsubsection{Laboratory Fire Tests}

Data from the ease of ignition test, the ASTM E 162 and ASTM E 84 flame spread tests, and the ASTM E 662 smoke density chamber test are given in table 4. The heat release rates and potential heats for the materials used in the room fire tests are presented in table 5. Results of the ease of ignition tests in table 4 showed that only the painted TS-GM, the B2II with three coats of paint, CK, SR, and one of three specimens of the BR2-1 produced measurable fuel contribution. The quarter-scale room fire tests of these five materials, i.e., tests 5R, 
27 and $27 \mathrm{R}, 10,11$, and 16 and 16R, resulted in room flashover. One of the two quarter-scale tests of the B2II having two coats of paint also resulted in room flashover even though the ease of ignition test showed no fuel contribution from the painted material. The same situation occurred with the BRI-1 material. An earlier study [1] demonstrated that the ease of ignition test could sometimes show fuel contribution for materials which would not flashover in the quarter-scale and fullscale room fire tests.

The correlation between flame spread tests and quarter-scale room fire tests is poor. Materials listed in table 4 which flashed over in the quarter-scale room fire tests had E 162 flame spread indices ( $I_{s}$ ) ranging from values as low as five for the B2II having three coats of paint and 21 for the SR to values as high as 97 for the painted TS-GM and 347 for the CK material. Materials which did not lead to room flashover had E 162 indices ranging from one for TS-GM, W-2, and the G insulation coated with 0-1001 to values of 60 for the BRI-2 and 103 for the $M$ acoustical material. Limited data were obtained with the ASTM E 84 test. Of the five insulations evaluated with this test, only the painted TS-GM had a flame spread classification (FSC) which exceeded the "fire-safe" FSC rating of 25. This painted insulation had a FSC of 35 and did flash over in the room fire test. However, another study [1] demonstrated that room flashover could occur with a material having a "fire-safe" FSC rating of 25.

There is also no direct relation between the data from the rate of heat release calorimeter and room fire development. For materials in table 5, which flashed over in the quarter-scale room fire tests, the peak rate of heat release varied from 159 to $353 \mathrm{~kW} / \mathrm{m}^{2}$, the maximum $60 \mathrm{~s}$ average rate ranged from 52 to $250 \mathrm{~kW} / \mathrm{m}^{2}$, and the peak $180 \mathrm{~s}$ average rate varied from 20 to $235 \mathrm{~kW} / \mathrm{m}^{2}$. However, for materials which did not exhibit flashover, the peak rates varied from 40 to $267 \mathrm{~kW} / \mathrm{m}^{2}$, the $60 \mathrm{~s}$ rate ranged from 14 to $248 \mathrm{~kW} / \mathrm{m}^{2}$, and the $180 \mathrm{~s}$ rate varied from 9 to $240 \mathrm{~kW} / \mathrm{m}^{2}$. Similarly, there is no direct relation between potential heat of a material and the contribution of the material to room fire growth. For materials which flash over in the room fire test, the potential heat values varied from 7040 to $27000 \mathrm{~kJ} / \mathrm{kg}$. ' The potential heat for the rest of the materials in table 5 ranged from about 2000 to $14130 \mathrm{~kJ} / \mathrm{kg}$. Potential heat values are accurate to within $\pm 200 \mathrm{~kJ} / \mathrm{kg}$. Thus, e.g., any real difference in the values existing between the two $G$ insulations having the two and three coats of paint would be obscured by the experimental variation inherent in the measurement.

The rate of smoke production in the quarter-scale room fire tests depends to a great extent on whether flashover occurred. In every case in this study where room flashover occurred, the peak smoke generation equalled or exceeded an optical density per meter, $0 . \mathrm{D} . / \mathrm{m}$, value of 13.8 over a path length of $0.15 \mathrm{~m}$. All the material which resulted in room flashover, with the exception of the painted TS-GM, had peak specific optical density, $\mathrm{D}_{\mathrm{m}}$, values ranging from 220 to 570 for the flaming 
exposure and 152 to 538 for the smoldering exposure with the E 662 smoke density chamber test. The painted TS-GM had D values of 43 and 66 for the flaming and smoldering exposures, respectively. On the other hand, materials which did not lead to flashover had $0 . \mathrm{D} . / \mathrm{m}$ values of 4.4 or less in the room tests, but had $D$ values as high as 572 and 582 for the flaming and smoldering modes with ${ }^{m}$ the $E 662$ test. These findings clearly show the difficulty in correlating smoke data from a laboratory test like the E 662 test with smoke production from the quarter-scale room fires.

\subsection{Full-Scale Tests and Comparisons with Quarter-Scale Tests}

The three painted hull insulations shown in table 2 were firetested in the full-size room to evaluate the room fire environment and generation of heat, smoke, and carbon monoxide for these insulations. Counterpart quarter-scale tests were conducted and comparisons were made with the full-scale tests to further demonstrate their ability to simulate full-size fires. Table 2 and figures 4 to 16 summarize the full-scale results and compare them with the results from their corresponding quarter-scale tests. In table 2 and in the following discussion, peak or maximum values refer only to those maximum values occurring at times up to and including the time of flashover, unless stated otherwise. The principal interest was in the peak level of fire buildup achievable up to and including room flashover. However, the fire development over the entire test duration of $1800 \mathrm{~s}$ for each of these tests was also of interest to the Navy and was included in figures 4 to 16.

Full-scale tests FS-2 and FS-4 reached flashover conditions in 58 and $51 \mathrm{~s}$, respectively. Their corresponding quarter-scale counterpart tests $5 \mathrm{R}, 27$, and $27 \mathrm{R}$ took between 79 and $94 \mathrm{~s}$ to reach flashover. The quarter-scale test 5 , which also scaled the full-size test FS-2, did not have sufficient fuel from the paint to maintain the fire long enough to ignite the newspaper flashover indicators. Each coat of paint used in test 5 was only about $0.08 \mathrm{~mm}$ in thickness versus the 0.10 to $0.13 \mathrm{~mm}$ thickness used in tests $5 \mathrm{R}$ and FS-2. However, test 5 did experience a peak interior air temperature of well over $600^{\circ} \mathrm{C}$, a condition which is frequently indicative of flashover. The doorway air temperature for test 5 was unavailable due to a malfunction of the thermocouple. Table 2 showed that full-scale test FS-3 experienced a maximum interior air temperature of only $310^{\circ} \mathrm{C}$. Interior air temperatures in the counterpart quarter-scale tests 7 and $7 R$ reached peak values of 380 and $400^{\circ} \mathrm{C}$, respectively. A peak doorway air temperature of $260^{\circ} \mathrm{C}$ was attained in FS-3. This compared with maximum doorway air temperatures of 260 and $290^{\circ} \mathrm{C}$ in tests 7 and $7 \mathrm{R}$, respectively. The aforementioned results reinforced the conclusion from another study [2] that materials which resulted in rapid flashover in the full-scale tests also did so in the quarter-scale room fire tests, while those materials which did not contribute significantly to the full-scale room fire development also did not contribute much to the model room fire growth. The same study concluded that time to reach flashover took longer in the quarter-scale test, which was also the case here. 
Heat release rates as high as $2570 \mathrm{~kW}$ and $3450 \mathrm{~kW}$ occurred in fullscale tests FS-2 and FS-4, respectively, by the time of flashover. Quarter-scale tests $5 \mathrm{R}$ and 27 , corresponding to FS-2 and FS-4, respectively, had peak full-scale equivalent heat release rates of 1220 and $2100 \mathrm{~kW}$, respectively. The repeat run, $27 \mathrm{R}$, of test 27 gave a peak full-scale equivalent of $4430 \mathrm{~kW}$. The total heat production or time integrated heat release, however, was about the same for tests 27 and 27R. All of these rates were well above steady state rates needed for flashover. Room fires with just gas burners as the fire source have shown that when steady state rates of heat release were employed, a rate as low as $340 \mathrm{~kW}$ maintained for about $300 \mathrm{~s}$ or, in the case of a rapid fire buildup, a rate of about $650 \mathrm{~kW}$ maintained for $45 \mathrm{~s}$ could cause flashover in this size room [2]. For test FS-3, the peak rate of heat production was $160 \mathrm{~kW}$ including the $90 \mathrm{~kW}$ from the ignition burner. Its corresponding quarter-scale test $7 \mathrm{R}$ had a maximum full-scale equivalent heat release rate of $110 \mathrm{~kW}$.

Thermal radiation levels at the floor in test $\mathrm{FS}-2$ reached $38 \mathrm{~kW} / \mathrm{m}^{2}$ at the time of flashover compared with a level of $34 \mathrm{~kW} / \mathrm{m}^{2}$ in its corresponding quarter-scale test 5R. The floor radiation reached $31 \mathrm{~kW} / \mathrm{m}^{2}$ at the time of flashover in test FS-4, but the counterpart quarter-scale tests 27 and $27 \mathrm{R}$ achieved radiation levels of only 18 and $14 \mathrm{~kW} / \mathrm{m}^{2}$, respectively, at the onset of flashover. However, the radiation flux at the floor for tests 27 and $27 \mathrm{R}$ was increasing rapidly at flashover, and the observed times for flashover were accurate only to within one or two seconds. Thus, the radiation levels for tests 27 and $27 \mathrm{R}$ could have been higher than $20 \mathrm{~kW} / \mathrm{m}^{2}$ when the newspaper flashover indicators ignited. This would then be consistent with the fact that newspaper ignites over a range of fluxes between 17 and $25 \mathrm{~kW} / \mathrm{m}^{2}$ [11]. For test FS-3, the radiation level at the floor peaked at $2.1 \mathrm{~kW} / \mathrm{m}^{2}$. Floor flux levels in its counterpart quarter-scale tests 7 and $7 \mathrm{R}$ reached maximum levels of 2.3 and $2.2 \mathrm{~kW} / \mathrm{m}^{2}$, respectively.

Peak carbon monoxide production at times up to and including flashover is shown in table 2 and was about $27 \mathrm{~g} / \mathrm{s}$ for both FS-2 and FS4. This compared with the peak full-scale equivalent values of 40,24 , and $42 \mathrm{~g} / \mathrm{s}$ in the quarter-scale tests $5 \mathrm{R}, 27$, and $27 \mathrm{R}$, respectively. However, little carbon monoxide was produced in test FS-3 and in its corresponding quarter-scale test $7 R$. Smoke data were not available for the full-scale tests due to a malfunction of the smoke measurement system. Peak smoke concentrations were available for the quarter-scale tests $5 R, 7 R, 27$ and $27 R$ and are shown in table 2 . The smoke levels in tests $5 R, 27$, and $27 R$ exceeded the limit of $16.4 \mathrm{oD} / \mathrm{m}$ for the measurement system. Only test $7 \mathrm{R}$ produced little smoke. The data on smoke, heat release, and generation of carbon monoxide from the quarter-scale fire tests 5 and 7 were not available, as reliable means for measuring these quantities were not ready until after tests 1 through 10 were completed. 


\subsection{Effect of Paint on Fire Performance of Hull Insulation}

An earlier study, involving quarter-scale room fire tests of insulations [1], indicated that decorative paints over two types of nitrile foams increased the surface flaming to the extent where flashover was imminent or had occurred in six of the seven cases (tests 6 to 9 and 11 to 13) where these foams were painted. The room fire tests of the unpainted nitrile foams (tests 4, 5, and 10) in that study resulted in interior and doorway air temperatures of less than $300^{\circ} \mathrm{C}$. A $3.9 \mathrm{~kW}$ ignition source was used for those tests. In the current work, a $5.6 \mathrm{~kW}$ ignition source was used for the tests shown in table 3 . Comparisons of test $5 R$ with test 2 and tests 27 and $27 R$ with tests 21 and $21 R$ in table 3 support the findings from the earlier study that decorative paints could often cause insulations to fail the criterion of no flashover over an $1800 \mathrm{~s}$ exposure to a moderately large fire.

The effect of paint on the fire development could have little effect on the room fire, as in test FS-3, or it could result in rapid transitory fire buildup to flashover with temperatures and thermal flux levels receding rapidly when the paint is consumed, as in test FS-2. Coatings of paint could also result in the fire involvement of the insulation such that a much more serious shipboard fire threat occurs, as in test FS-4. Figure 10 shows that in full-scale test FS-2, with the TS-GM insulation and coatings of 0-634 and chlorinated alkyd 124 paints, the coatings enhanced the fire such that the radiant flux to the floor exceeded $20 \mathrm{~kW} / \mathrm{m}^{2}$, the threshold value for flashover, for a post-flashover duration of $50 \mathrm{~s}$. For full-scale test FS-4 with the B2II insulation and 0-634 coating, the fire reached flashover in $51 \mathrm{~s}$. After the paint was consumed, the interior and doorway air temperatures receded until about $135 \mathrm{~s}$ at which time fire involvement of the B2II insulation began to increase dramatically due to the intense thermal environment in the room. Figure 12 shows that the flux to the floor in test FS-4 gradually increased to above the threshold value of $20 \mathrm{~kW} / \mathrm{m}^{2}$ after reaching a low of about $11 \mathrm{~kW} / \mathrm{m}^{2}$ at $165 \mathrm{~s}$. It was $420 \mathrm{~s}$ into the test before the flux level at the floor receded below $20 \mathrm{~kW} / \mathrm{m}^{2}$ again.

The quarter-scale counterparts of FS-2 and FS-4, i.e., tests $5 R$, 27 , and $27 R$, also experienced flashover. For tests 7 and $7 R$, the room was lined with fibrous glass hull insulation $G$ and covered by two coats of the vapor barrier 0-1001. These tests, like their corresponding full-scale test FS-3, did not exhibit flashover. Test 8 was similar to tests 7 and $7 R$, except that its surface had an additional topcoat of chlorinated alkyd 124 paint over the 0-1001. The chlorinated alkyd paint did not increase the fire risk of the insulation $G$. Test 6 , with the TS-GMG material painted with 2 coats of $0-9788$, also did not approach flashover conditions. Tests 22, 22R, 27, and $27 R$, with the painted B2II insulations, demonstrated the importance of paint thickness to room fire growth. Tests 22 and $22 \mathrm{R}$ had 2 coats of the $0-634$, but only test 22 achieved room flashover. Tests 27 and $27 R$, with 3 coats of $0-634$, reached flashover in $91 \mathrm{~s}$ and $79 \mathrm{~s}$, respectively, compared with a time of $101 \mathrm{~s}$ for test 22 . 


\subsection{Test Protocol for Quarter-Scale Test}

A recommended test protocol on the determination of the flashover potential of hull insulation using the quarter-scale room fire test is given in the appendix. The following discussion gives some of the rationale for the protocol development. In the construction of the room, there is a need to simulate the actual construction as much as is possible. Shipboard hull insulation is generally attached to metal bulkheads with adhesive or impaled on metal studs on the bulkhead. Thus, the quarter-scale room should be constructed from either aluminum or steel sheet or plate to assure proper adhesion between the insulation and the metal substrate when adhesives are used and to provide a similar substrate which has a high thermal sink. Aluminum construction is recommended for its lower weight for the same wall thickness, making refitting operations easier. As for burner location the center of the floor is not suitable as the flames from any reasonably sized fire cannot directly contact the wall material. Placement of the ignition source against the back wall or in a rear corner are two practical alternatives. Corner placement appears to be more desirable as the wall insulation would be evaluated under the more demanding fire exposure for any given rate of heat release for the burner. The severity of the ignition source should be large enough to adequately assess the fire hazard potential of materials, but should not be so large as to overwhelm the material being evaluated. The $5.6 \mathrm{~kW}$ source recommended in the protocol represents approximately the quarterscale version of a small upholstered chair burning in a room. A $5.6 \mathrm{~kW}$ burner rate in the corner of the room, maintained for $300 \mathrm{~s}$, represents about one-fourth of the rate needed for flashover of a quarter-scale room lined with fire-exposed fibrous glass hull board [2]. The test insulation itself must then contribute three times the burner rate of heat release in order to achieve flashover of the room. (Fire-exposed hull board is fibrous glass insulation which has had much of the organic binder burned of $f$, leaving a relatively inert material. This was accomplished by subjecting the room lined with the insulation to a $11.3 \mathrm{~kW}$ burner exposure for $900 \mathrm{~s}$ several hours before actual testing began.)

Measurement of the degree of fire buildup up to and including the time of flashover, if it should occur, can be obtained by monitoring the rise in air temperature at the doorway and near the center of the ceiling. Although $0.05 \mathrm{~mm}$ wire thermocouples were used in this study for precision measurement of air temperatures, they are difficult to prepare and are vulnerable to breakage. It is suggested that thermocouples fabricated from $0.25 \mathrm{~mm}$ diameter chromel and alumel wires be used for durability. For the room test lined with the fire-exposed fibrous glass and a burner rate of 5.6 $\mathrm{kW}$, steady temperature conditions are reached by $1200 \mathrm{~s}$. In order to get an indication of the variability of air temperatures expected under such steady conditions for facilities following the recommended test protocol as given in the appendix, the above test with the fire-exposed insulation was run at three facilities. These facilities were the National Bureau of Standards, the David Taylor Naval Ship Research and Development Center in Annapolis, Maryland, and 
the Bath Iron Works in Maine. At $1200 \mathrm{~s}$ into the test, the air temperatures, as measured with $0.25 \mathrm{~mm}$ wire thermocouples at these three facilities, were all within $\pm 10^{\circ} \mathrm{C}$ of $240^{\circ} \mathrm{C}$ at $25 \mathrm{~mm}$ below the doorway and within $\pm 10^{\circ} \mathrm{C}$ of $355^{\circ} \mathrm{C}$ at $25 \mathrm{~mm}$ below the center of the ceiling.

The basic criterion for limiting the fire growth potential of shipboard interior finish materials requires that the insulation or combination of insulation and coating materials must not lead to flashover of the room over the exposure period of $1800 \mathrm{~s}$ using the prescribed burner rate of heat release of $5.6 \mathrm{~kW}$. However, the degree of fire buildup that is achievable, short of $\mathrm{flashover,} \mathrm{is}$ also important in determining the fire hazard of materials. It has been demonstrated that the air temperatures inside the room and in the doorway provide reliable indications of the degree of fire buildup [1,2]. Table 3 gives a comparison of peak air temperatures near the ceiling and near the top of the doorway for all of the quarter-scale room fire tests. Earlier work [1] suggested that flashover conditions could be expressed in terms of the temperature levels for the hot air at the doorway and inside the room. In that work, the data showed that even interior air temperatures of about $600^{\circ} \mathrm{C}$ could result in the ignition of the flashover indicators in the room. For example, tests 45,33 , and 30 in that study had peak interior air temperatures of 587,604 , and $616^{\circ} \mathrm{C}$, respectively, at times up to and including the time of flashover. The same study showed that peak doorway air temperatures could be as low as 427 to $451^{\circ} \mathrm{C}$ at times up to and including the time when flashover occurred. For instance, tests 20 and 36 in that test series exhibited peak doorway air temperatures of $427^{\circ} \mathrm{C}$ while test 33 had a maximum doorway air temperature of $451^{\circ} \mathrm{C}$. All three tests experienced flashover and had interior air temperatures of over $600^{\circ} \mathrm{C}$.

An examination of the data in table 6 further substantiated such a correlation between room interior air and doorway air temperatures and flashover conditions. Tests $5 \mathrm{R}, 10,11,14 \mathrm{R}, 16,16 \mathrm{R}, 22,27$, and $27 \mathrm{R}$ in table 6 experienced flashover. Of these tests, all experienced interior and doorway air temperatures of at least $650^{\circ} \mathrm{C}$ and $430^{\circ} \mathrm{C}$, respectively, except for test 16 . Test 16 reached flashover at $550 \mathrm{~s}$ and had peak interior and doorway air temperatures of 590 and $410^{\circ} \mathrm{C}$, respectively. A repeat test, $16 \mathrm{R}$, of test 16 experienced flashover at $1485 \mathrm{~s}$ and peak air temperatures of 790 and $480^{\circ} \mathrm{C}$ at the interior and doorway, respectively. There was a chance that burning material in the form of surface flaking may have ignited the newspaper flashover indicators in test 16 , as pieces of material began falling from the ceiling as early as $390 \mathrm{~s}$ into the test. It is also possible to have interior temperatures much higher than $600^{\circ} \mathrm{C}$ and with no ignition of the flashover indicators, as in test 5. Test observations indicated that flames in that test were localized and spread only near the interior thermocouple before receding. Unfortunately, the doorway air temperatures were unavailable at the $25 \mathrm{~mm}$ and $51 \mathrm{~mm}$ locations below the doorway to help in understanding the fire development. The thermocouples at these locations malfunctioned. However, the doorway thermocouple at the $104 \mathrm{~mm}$ location gave a reading of only $60^{\circ} \mathrm{C}$ versus the lowest recorded value of $340^{\circ} \mathrm{C}$ (test 14 ) at that location for those tests where flashover occurred. Thus, flashover in the quarterscale test could be defined as the room condition where the peak 
interior air temperature is at least $600^{\circ} \mathrm{C}$ and the maximum doorway air temperature is also at least $400^{\circ} \mathrm{C}$. The latter requirement is used to help avoid giving a flashover classification to the room fire condition where localized fire involvement along the ceiling resulted in interior air temperatures exceeding the "flash-over threshold" of $600^{\circ} \mathrm{C}$ without an accompanying flashover. From the aforementioned discussion, it appears then that the fire risk potential of hull insulations and coatings can be assessed solely by the peak air temperatures achievable in the quarter-scale test.

Measurement of the peak air temperatures in the quarter-scale test, however, is complicated by the stratification of air temperatures inside the room and at the doorway. Boundary layer effects, thermal losses to the surface, and out-gassing or fuel generation at the surface also affect the temperature gradient near the ceiling. Constriction of the flow through the doorway and stratification of the hot air affect the temperature gradient at the doorway. Consequently, the room fire test data were analyzed to find the most suitable heights at the doorway and below the ceiling in the room for measuring peak air temperatures with a minimum number of thermocouples. The data in table 6 showed that peak doorway air temperatures usually occurred at $25 \mathrm{~mm}$ below the doorway lintel. However, in tests $5 \mathrm{R}, 10$, and $14 \mathrm{R}$, the peak value occurred at the 51-mm location. Maximum interior temperatures usually occurred at the 25-mm location below the ceiling, but in many cases, the peak values were measured at greater distances away from the ceiling. Sometimes this may be a consequence of the material separating from the ceiling and then possibly burning in the vicinity of the lower thermocouples, e.g., in test 19. More often, it may be the result of an inverted thermal stratification arising from the burning behavior of the material. At any rate, the quarter-scale test should have the capability of detecting these peak temperatures which affect the radiation flux to the lower part of the room which in turn determines the degree of fire buildup. The data in table 6 show that the maximum air temperatures could occur at an elevation as low as $51 \mathrm{~mm}$ below the doorway lintel and at 51 to $102 \mathrm{~mm}$ below the ceiling. Based on these data, as well as on past observations of quarter-scale fire tests, it is recommended that, in the test protocol developed for the quarter-scale test, thermocouples be used at the 25 and $51 \mathrm{~mm}$ locations below the top of the doorway and at $25 \mathrm{~mm}$ and $76 \mathrm{~mm}$ below the ceiling.

\section{CONCLUDING REMARKS}

1. No reliable correlations exist between the laboratory materials fire property test performance and full-scale or quarter-scale room fire test behavior of the shipboard insulations evaluated. This is in accord with earlier findings involving hull insulation [1].

2. Quarter-scale room fire testing demonstrated that it is a reliable indicator of full-scale room fire behavior for the three cases discussed in this report where there was flashover in two tests 
and only a low level fire buildup in the third test. This was consistent with prior studies involving a variety of materials $[1,2]$.

3. Cork, silicone rubber SR, and the polyvinyl chloride-polyvinyl acetate $B R 1-1$ and $B R 2-1$ tiles failed the requirement of no flashover in the quarter-scale room fire test over a $1800 \mathrm{~s}$ test period.

4. Vapor barrier 0-1001 did not significantly affect the fire performance of fibrous glass hull board.

5. Decorative paints such as $0-634$ and the Navy's chlorinated alkyd formula 124 could transform an otherwise fire-safe insulation into a fire-risk material.

6. A test protocol has been developed for the quarter-scale room fire test and is included in the appendix.

7. Round robin evaluation of the quarter-scale room fire test among at least three participating laboratories is recommended as a logical follow-up to this work. The study should involve a variety of materials having a wide range of fire properties with at least three tests of each material. The results from all three laboratories should be analyzed to demonstrate the repeatability of results within each laboratory and the reproducibility among laboratories before this protocol is adopted for general use in material specifications. The acceptable level of reproducibility should be determined from the fire situations being replicated.

\section{ACKNOWLEDGEMENTS}

Appreciation is expressed to Mr. Charles Veirtz, who performed the quarter-scale tests; to Messrs. Charles Veirtz and Oscar Owens for conducting the full-scale tests, and to Mr. J. N. Breese for the data reduction and preparation of most of the figures in the report.

This study was supported by the Naval Sea Systems Command, Department of the Navy, under the direction of Messrs. William Dunham and John Pinto.

\section{REFERENCES}

1. Lee, B.T.; Breese, J.N.; Submarine Compartment Fire Study - Fire Performance Evaluation of Hull Insulation. Nat. Bur. Stand. (U.S.) NBSIR 78-1584; 1979 May.

2. Lee, B.T. Quarter-Scale Modeling of Room Fire Tests of Interior Finish. Nat. Bur. Stand. (U.S.) NBSIR 81-2453; 1982 March. 
3. Lawson, J.R.; Parker, W.J.; Development of an Ease of Ignition Test Using a Flame Exposure. Nat. Bur. Stand. (U.S.) NBSIR 822503; 1982 June.

4. Standard Test Method for Surface Flammability of Materials Using a Radiant Heat Energy Source. ASTM E 162. Philadelphia, PA: American Society for Testing and Materials; 1981.

5. Standard Test Method for Surface Burning Characteristics of Building Materials. ASTM E 84. Philadelphia, PA: American Society for Testing and Materials; 1981.

6. Tordella, J.; Twilley, W.; Development of a Calorimeter for Simultaneously Measuring Heat and Mass Loss. Nat. Bur. Stand. (U.S.) NBSIR in preparation.

7. Standard Test Method for Potential Heat of Building Materials. NFPA 259-1976. Boston, MA: National Fire Protection Association; 1976.

8. Standard Test Method for Specific Optical Density of Smoke Generated by Solid Materials. ASTM E 662. Philadelphia, PA: American Society for Testing and Materials; 1979.

9. Lee, B.T. Effect of Ventilation of the Rates of Heat, Smoke, and Carbon Monoxide Production in a Typical Jail Cell Fire. Nat. Bur. Stand. (U.S.) NBSIR 82-2469; 1982 March.

10. Parker, W.J. Calculations of the Heat Release Rate by Oxygen Consumption for Various Applications. Nat. Bur. Stand. (U.S.) NBSIR 81-2427-1; 1982 March.

11. Fang, J.B. Fire Buildup in a Room and the Role of Interior Finish Materials. Nat. Bur. Stand. (U.S.) Tech. Note 879; 1975 June. 


\section{APPENDIX A}

Test Protocol on the Determination of the Flashover Potential of Shipboard Hull Insulation Using a Quarter-Scale Room Fire Test

Al. SCOPE

Al.1 Scope. This method describes a procedure to determine the flashover potential of shipboard hull lining materials subjected to a fire exposure in a mock-up room.

Al.2 The method gives an indication of the potential room fire buildup up to and including room flashover. It yields a time from the introduction of the fire exposure until the moment of flashover, or until the peak room air temperature is reached, if flashover does not occur.

\section{A2. JUSTIFICATION}

A2.1 In the interest of reducing both the set-up time and cost associated with fire testing in a full-size room, herein defined as a $3.0 \times 3.0 \times 2.4 \mathrm{~m}$ high enclosure having a $0.76 \times 2.03 \mathrm{~m}$ high doorway, a one-quarter scale room fire test was devised for determining the flashover potential of lining materials exposed to fire.

\section{A3. EQUIPMENT}

A3.1 The quarter-scale room shall be constructed from $6.4 \mathrm{~mm}$ aluminum or steel sheet and shall form a box having a ceiling and four sides with air tight joints. The box shall sit on a floor fabricated with the same material. The interior dimensions of the fully lined quarter-scale room are $0.76 \times 0.76 \times 0.61 \mathrm{~m}$ high. A doorway is located at the center of one wall and must be $0.50 \mathrm{~m}$ wide and $0.43 \mathrm{~m}$ high to secure the proper ventilation and fire development. The distance between the finished ceiling and the top of the doorway must be $178 \mathrm{~mm}$. The floor of the model room must extend at least $0.30 \mathrm{~m}$ outside of the doorway. The box is removable to allow for application of paint and/or ceiling and wall covering. The entire base of the box in contact with the floor shall be made air tight.

A3.2 A porous ceramic plate diffusion flame burner shall be used as the fire source. The burner shall be $89 \times 89 \times 76 \mathrm{~mm}$ high consisting of a horizontal porous plate area of 76 × $76 \mathrm{~mm}$ with a $6.4 \mathrm{~mm}$ wide steel plate perimeter and steel plate sides and bottom.

A3.3 Four chromel-alumel thermocouples, fabricated from $0.25 \mathrm{~mm}$ diameter (Brown and Sharpe 30 gage) wire, shall be used -- 25 and $76 \mathrm{~mm}$ below the center of the overhead and 25 and $51 \mathrm{~mm}$ below the top of the doorway. 


\section{A4. PROCEDURE}

A4.1 The test material shall fully line the walls and ceiling. As much as possible, the material shall be mounted in the same manner as is used on board ship.

A4.2 Prior to testing, the fully lined test room shall be conditioned for at least 24 hours at a relative humidity between $50 \pm 10$ percent and a temperature of $23 \pm 5^{\circ} \mathrm{C}$.

A4.3 The diffusion burner shall be positioned on the floor snugly against one rear corner of the test room such that there is no air gap between the burner and the two walls. A flow rate of $150 \mathrm{ml} / \mathrm{s}(0.32$ CFM) of methane shall be used to produce a constant heat input of $5.6 \mathrm{~kW}$ (320 Btu/min) for the duration of the test.

A4.4 The test data from the four thermocouples shall be recorded continuously during the test.

A4.5 The primary data generated by this test will be the time to room flashover, if it occurs, and the maximum temperature if flashover is not reached. Flashover is characterized by thermal flux levels equal to or greater than $20 \mathrm{~kW} / \mathrm{m}^{2}$ at the floor level. This corresponds to interior temperatures of $600^{\circ} \mathrm{C}$ and higher and doorway temperatures of $400^{\circ} \mathrm{C}$ and higher. For the purpose of qualification/acceptance, flashover is defined here as that fire condition where one of the interior thermocouple measurements reaches $600^{\circ} \mathrm{C}$ and one of the doorway measurements reaches at least $400^{\circ} \mathrm{C}$. For qualification/acceptance of a material, room flashover shall not occur within $1800 \mathrm{~s}$.

A4.6 Color $35 \mathrm{~mm}$ slides be taken at $15 \mathrm{~s}$ intervals during the first $180 \mathrm{~s}$ and at $30 \mathrm{~s}$ intervals thereafter to document the growth of the fire.

\section{A5. SUMMARY}

The quarter-scale room test procedure described here provides a relatively low cost, and generally reproducible, method for determining the flashover potential of materials used to line the interior surfaces of shipboard compartments. The lining materials may be insulation, paint (used over lining materials), sheathing, acoustic panels, or the like. 


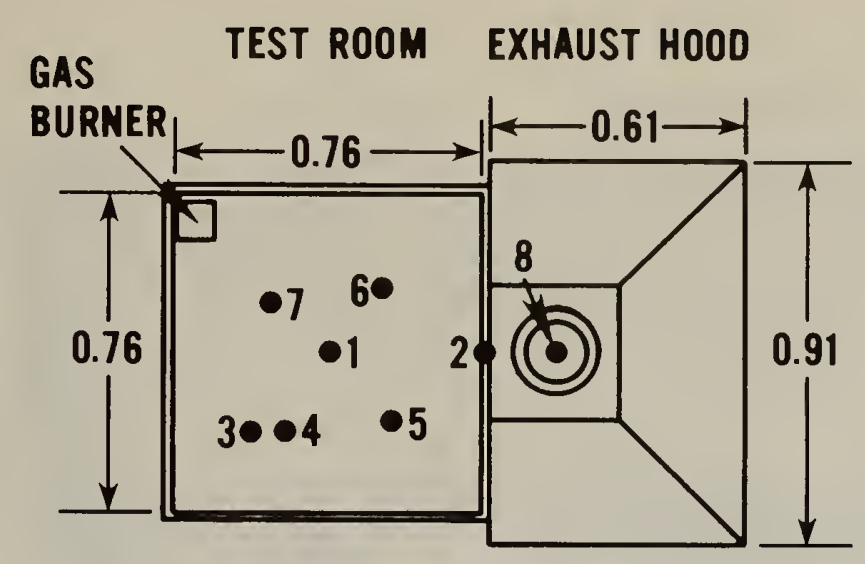

\section{PLAN VIEW (ceiling of room removed)}

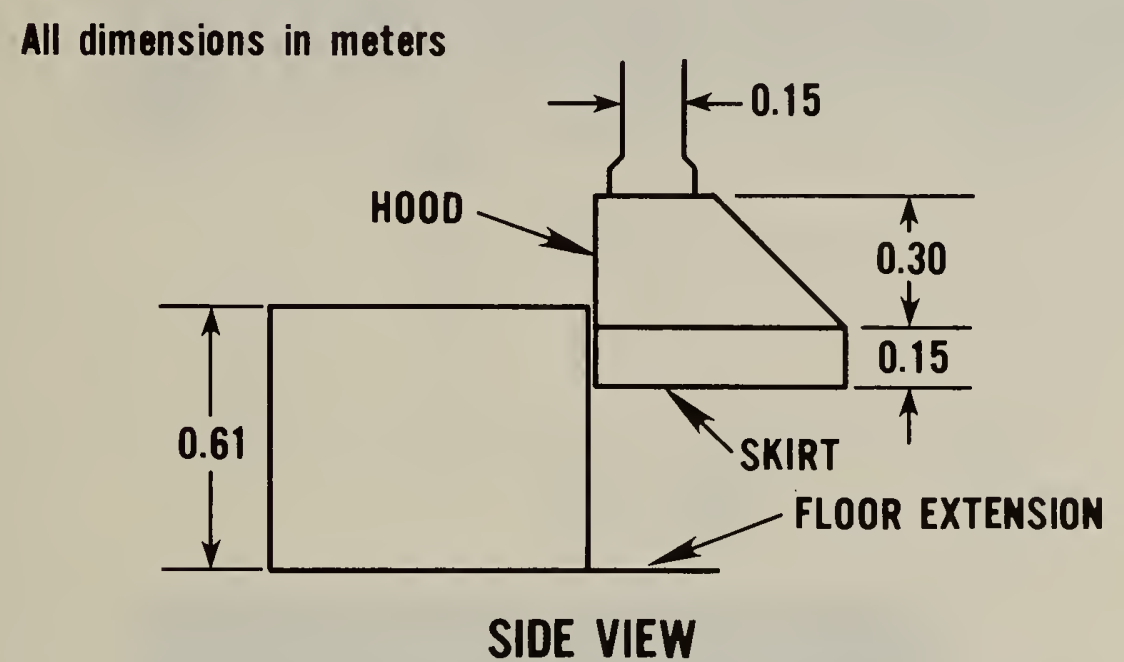

$\underline{\text { Station }}$

1

2

3

4 to 7

8

$\underline{\text { Instrument }}$

- Vertical strand of seven $0.05 \mathrm{~mm}$ thermocouples at 25, $51,102,203,305,457$ and $610 \mathrm{~mm}$ down from center of ceiling.

- Vertical strand of six $0.05 \mathrm{~mm}$ thermocouples located along the centerline of the doorway at distances of 25, 51, 102, 203, 254, and $356 \mathrm{~mm}$ below the top of the doorway .

- Thermal flux gauge on floor.

- General vicinity for newspaper flashover indicators on floor.

- Thermocouple, pitot tube, gas sample port $\left(\mathrm{O}_{2}, \mathrm{CO}, \mathrm{CO}_{2}\right)$, and smoke meter in stack.

Figure 1. Layout and Instrumentation for Quarter-Scale Test 


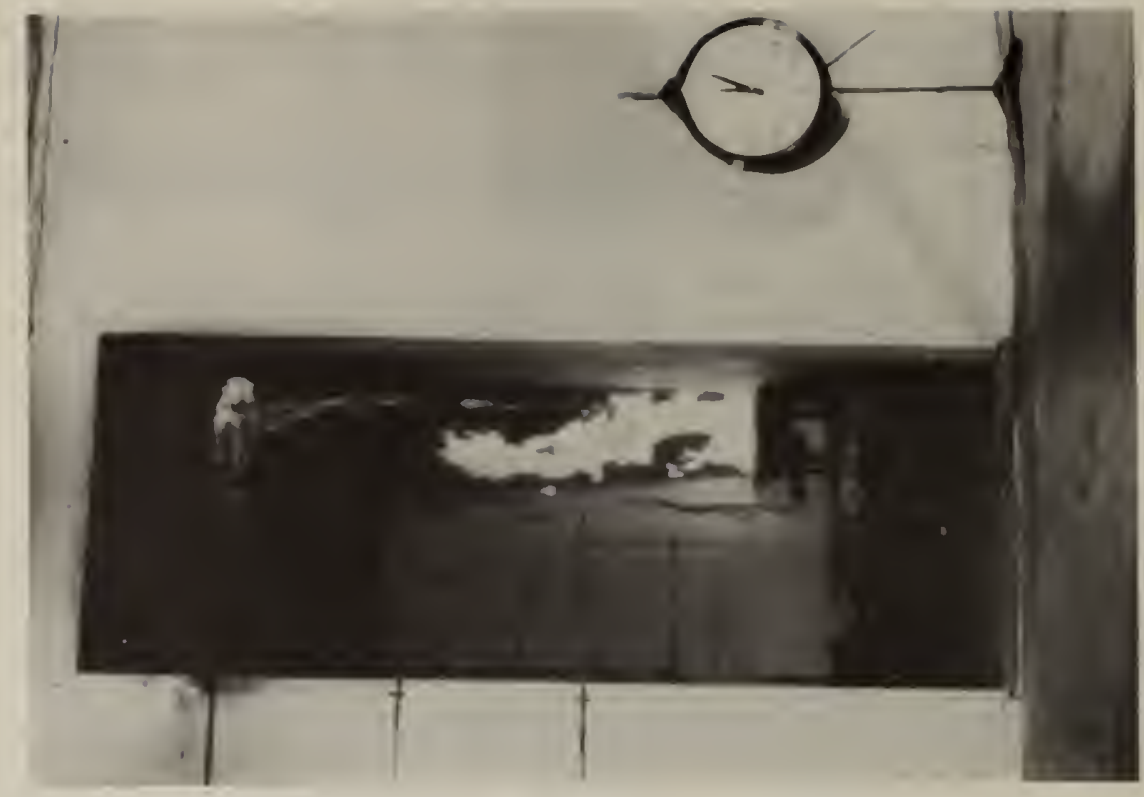

0
0
0
0
0
0
0
0
1
-1
7
7
0

$n$
$n$
0
0

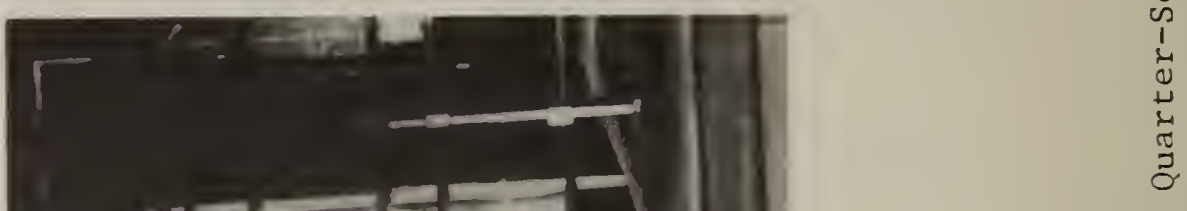

$\stackrel{\sim}{0}$

先 


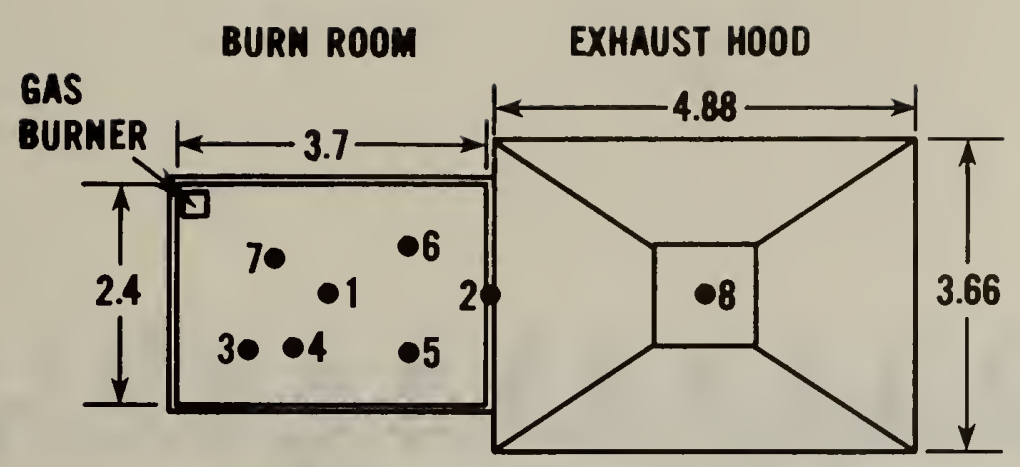

PLAN VIEW (ceiling of room removed)

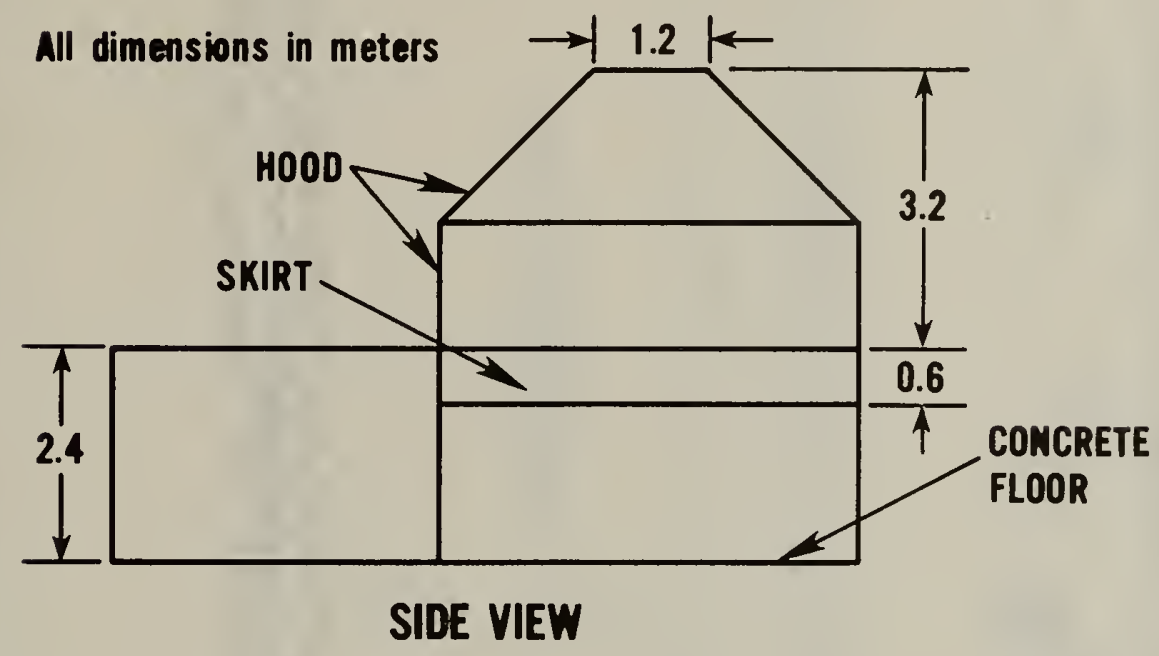

$\underline{\text { Station }}$

1

2

3

4 to 7

8

\section{Instrument}

- $0.51 \mathrm{~mm}$ (24 gauge) thermocouples at $0,0.03,0.10$, $0.60,0.90,1.20,1.50,1.80,2.10,2.34$, and $2.44 \mathrm{~m}$ below center of ceiling. $0.05 \mathrm{~mm}$ thermocouples at $0.10,0.60,1.20,1.80$ and $2.34 \mathrm{~m}$ below center of ceiling.

$-0.51 \mathrm{~mm}$ (24 gauge) thermocouples at $0.03,0.10,0.30$, $0.50,0.70,0.90,1.10,1.30,1.50,1.78$, and $1.90 \mathrm{~m}$ from top of doorway. $0.05 \mathrm{~mm}$ thermocouples at 0.10 , $0.50,0.90,1.30$ and $1.78 \mathrm{~m}$ from top of doorway.

- Thermal flux gauge on floor.

- General vicinity for newspaper flashover indicators on floor.

- Thermocouple, pitot tube, gas sample port $\left(\mathrm{O}_{2}, \mathrm{CO}\right.$, $\mathrm{CO}_{2}$ ), and smoke meter in stack. 


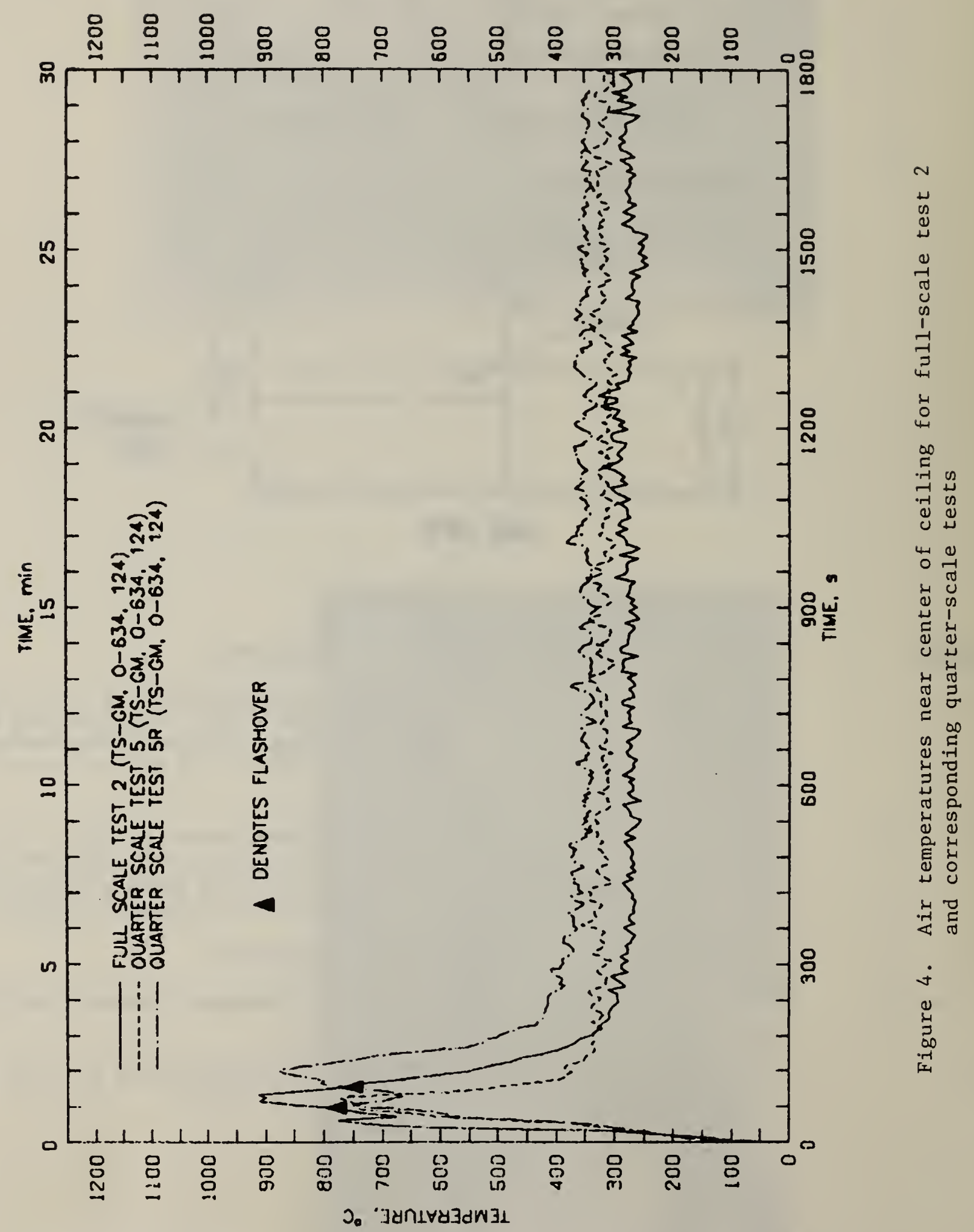




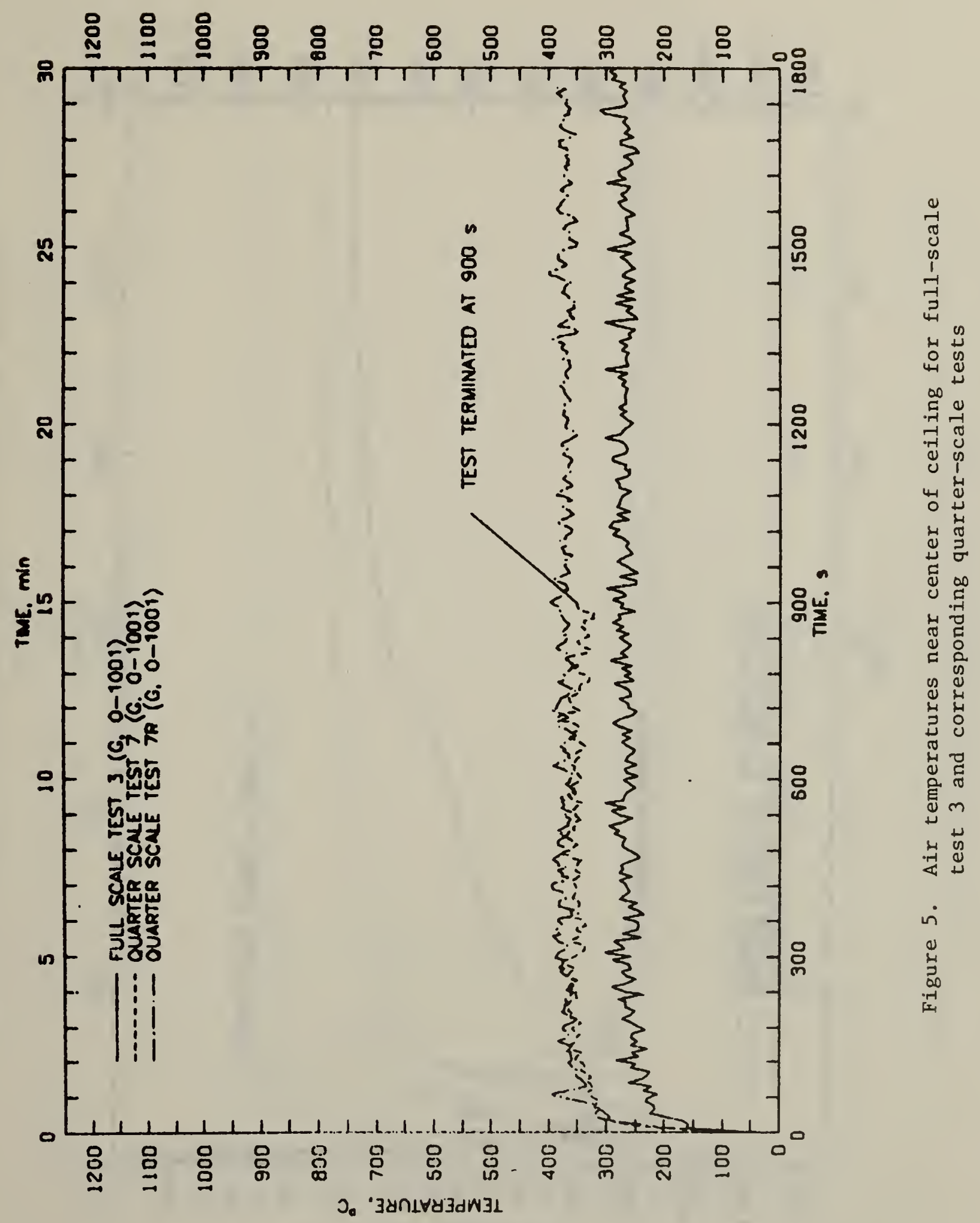




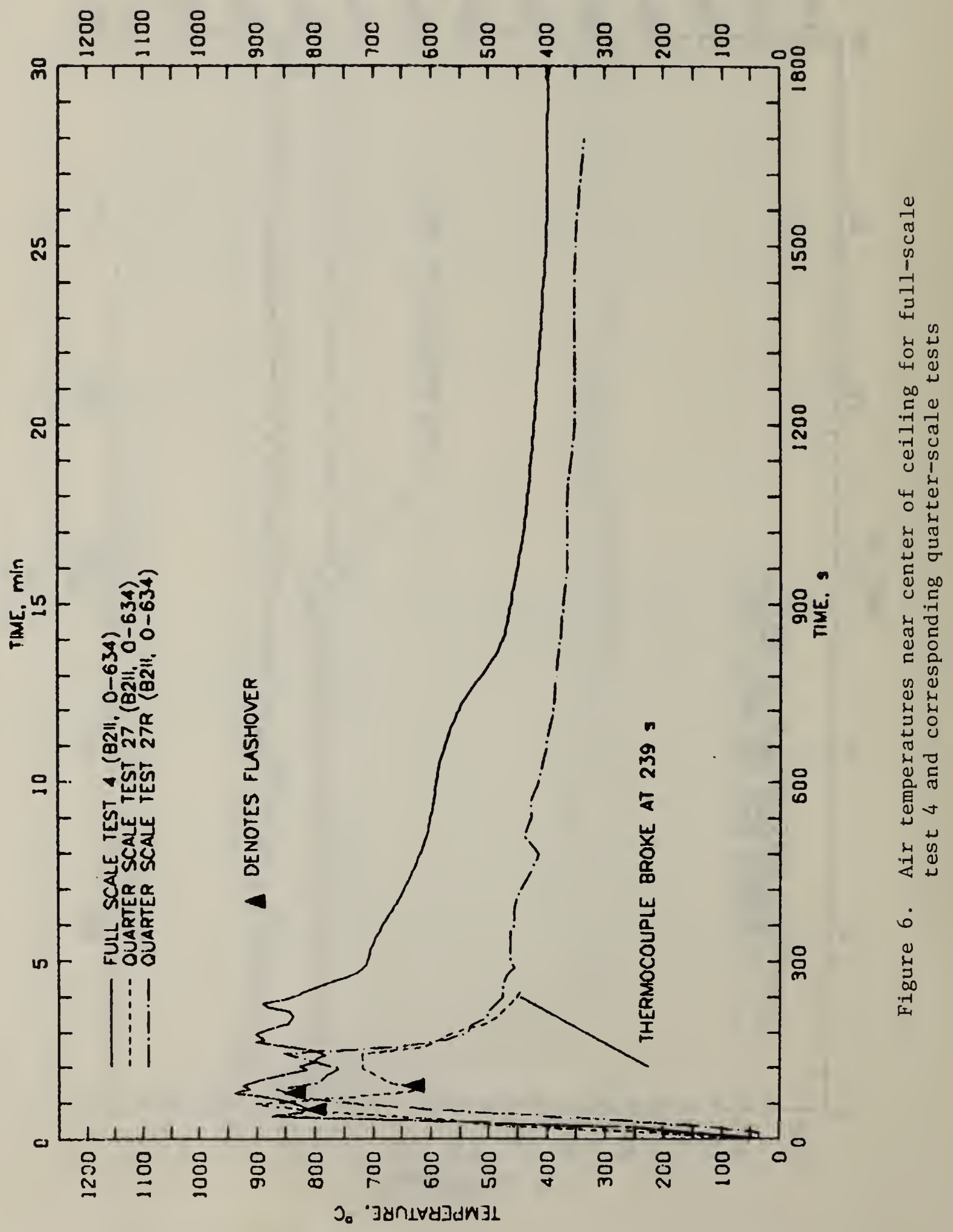




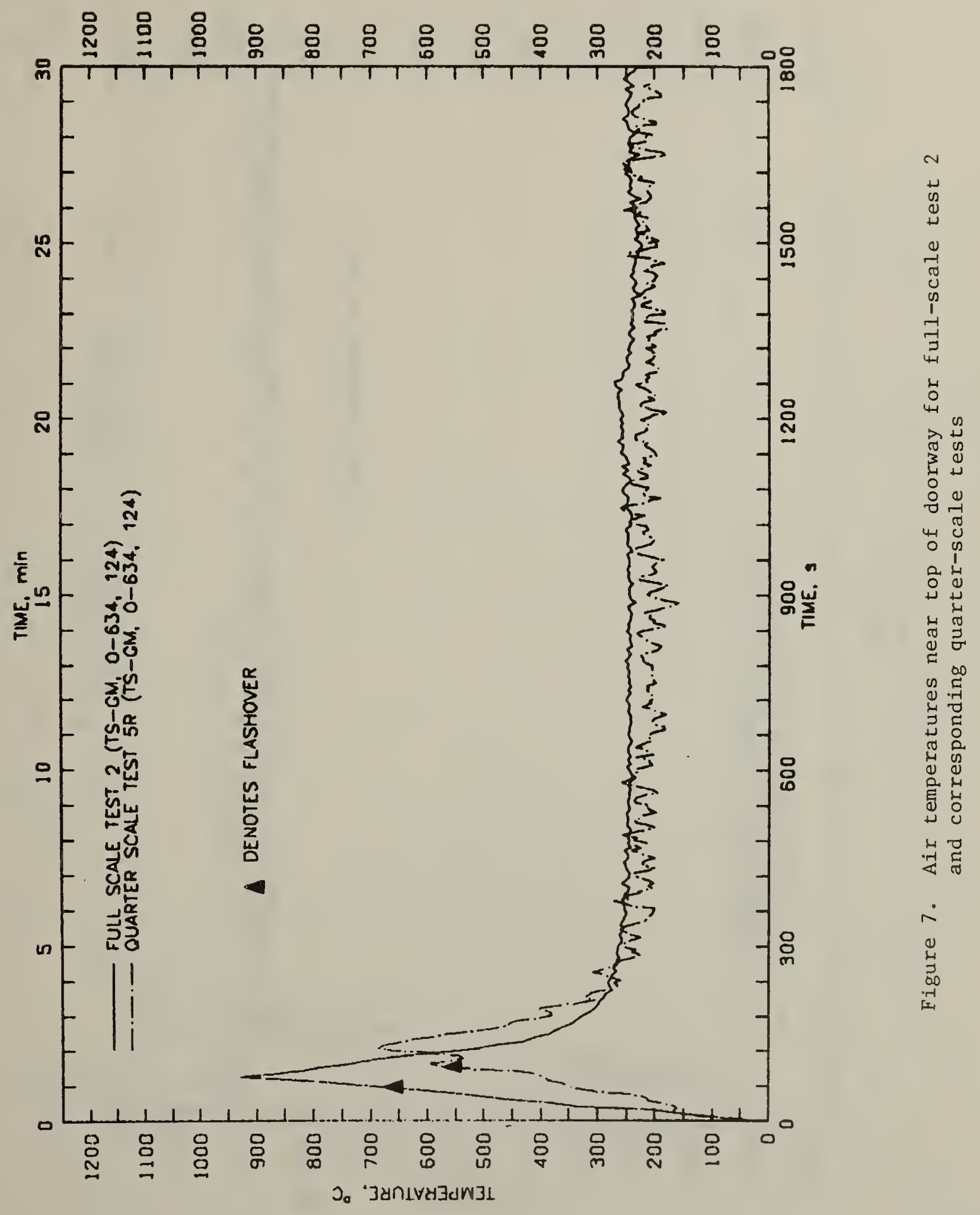




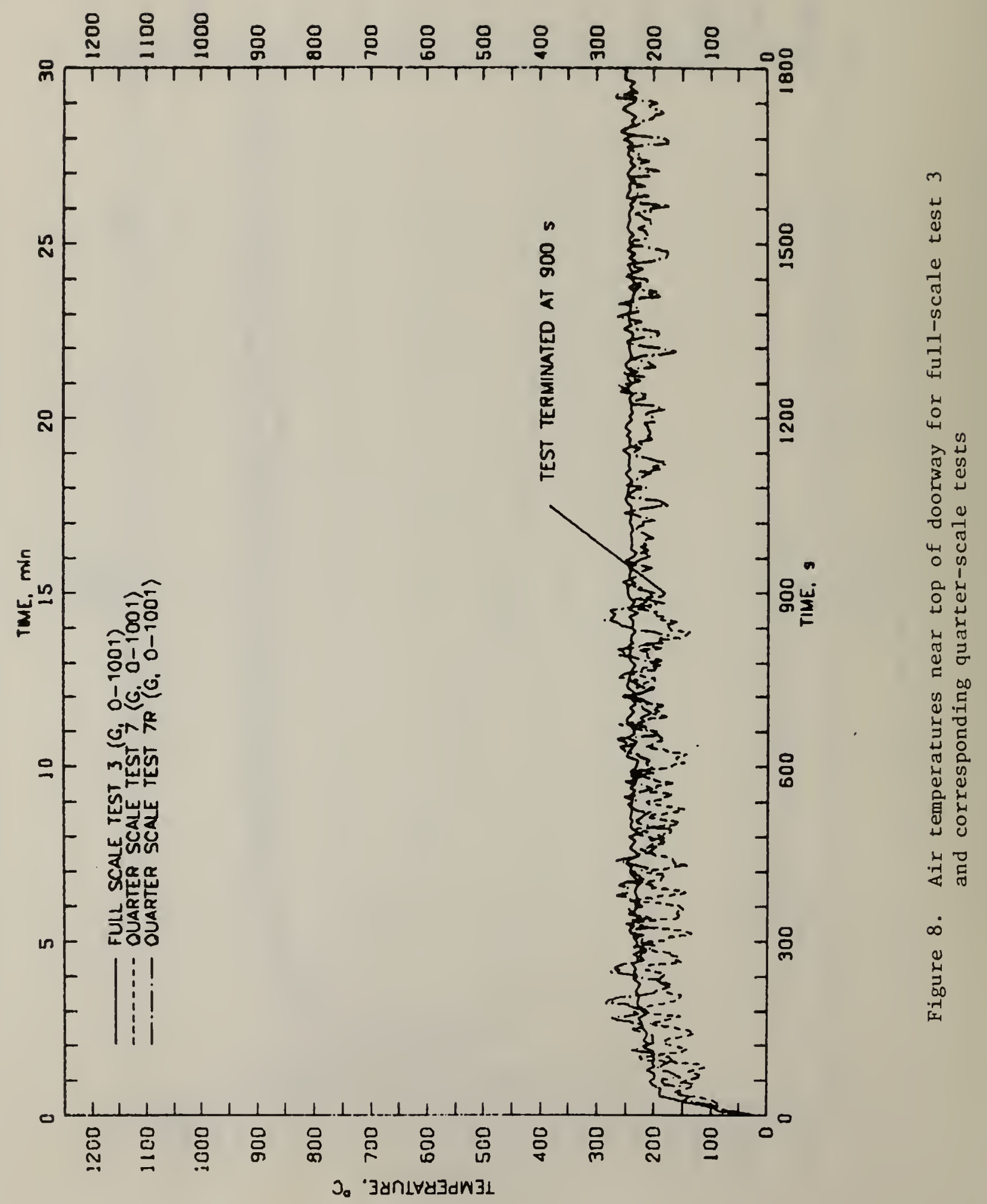




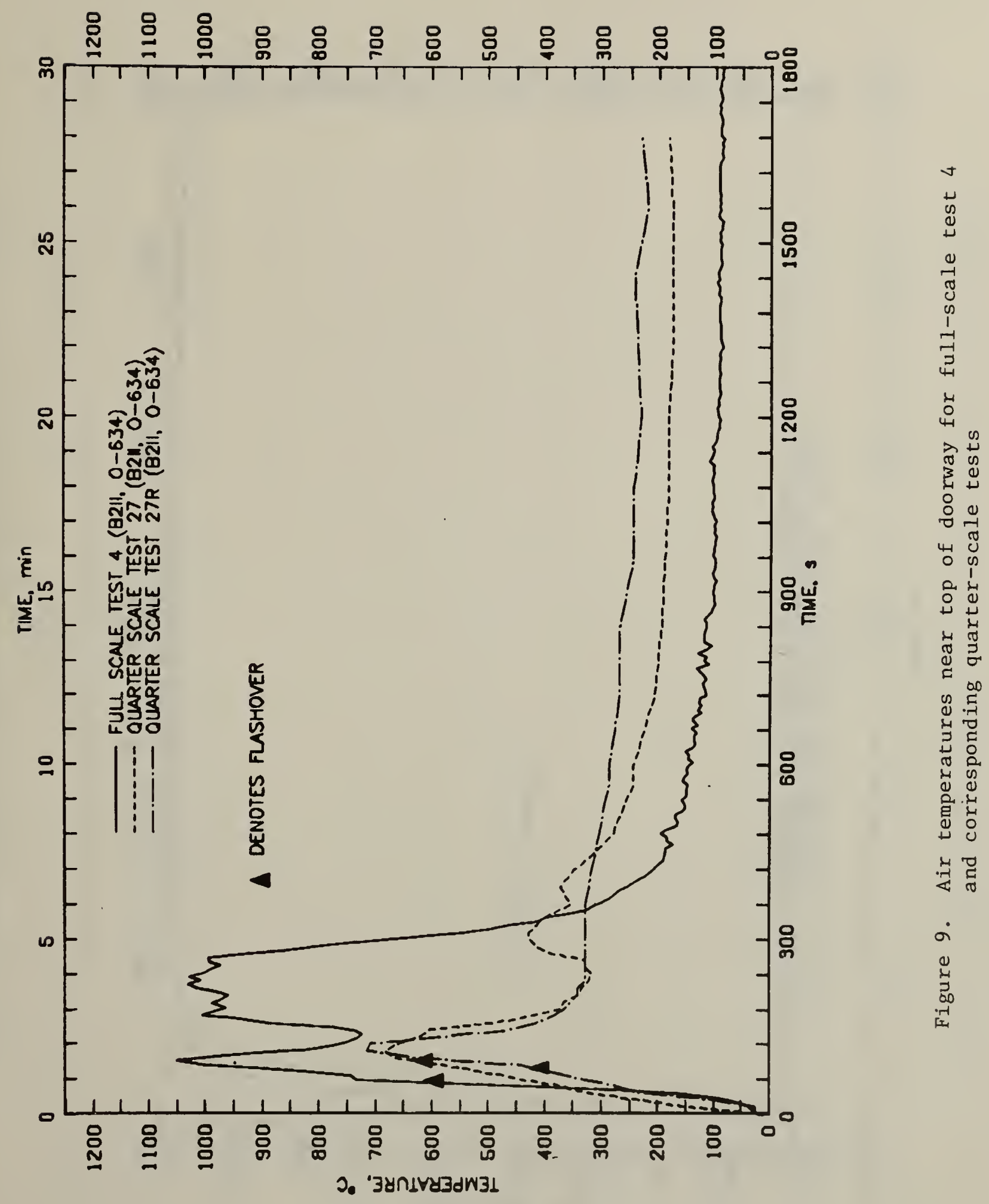




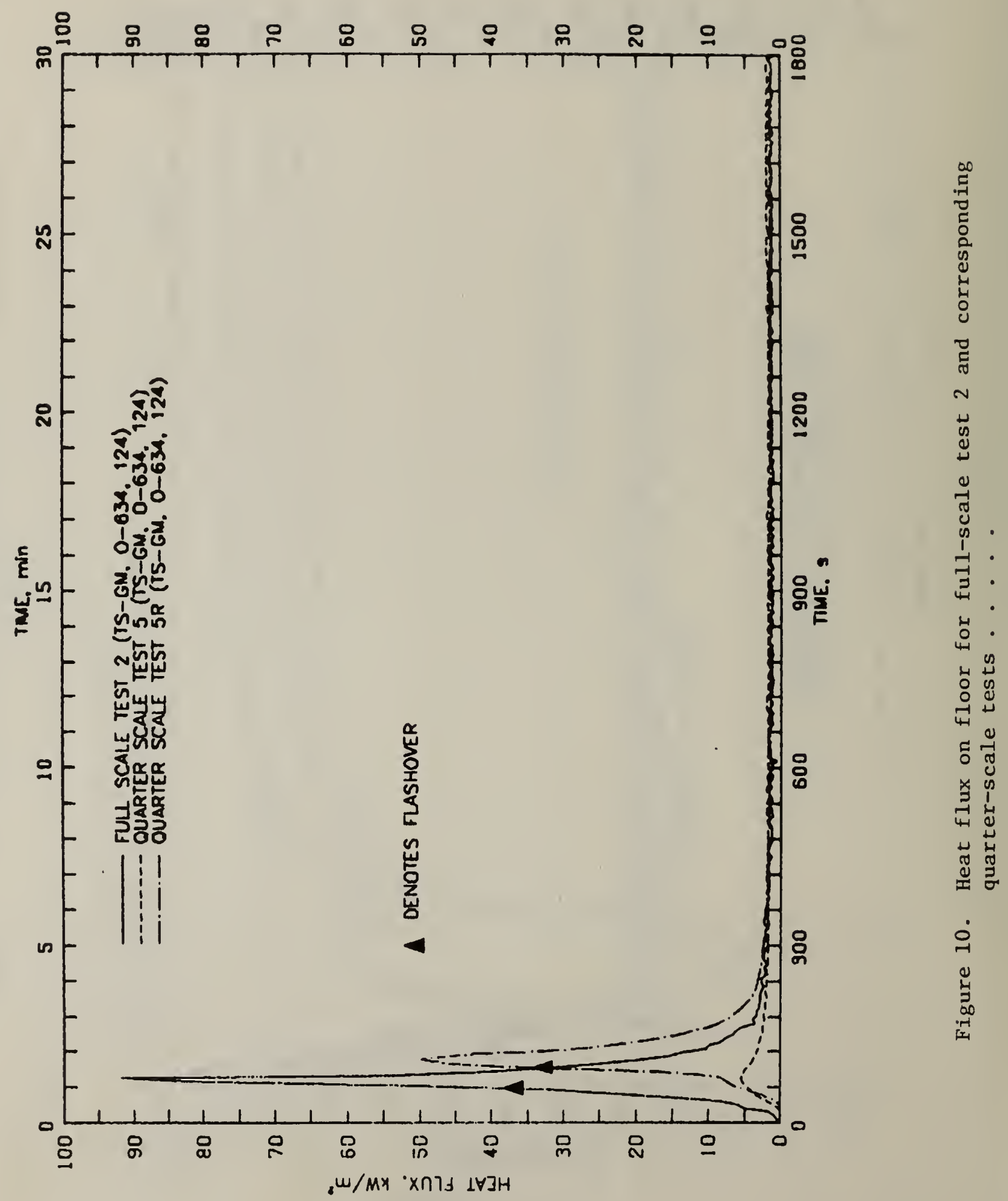




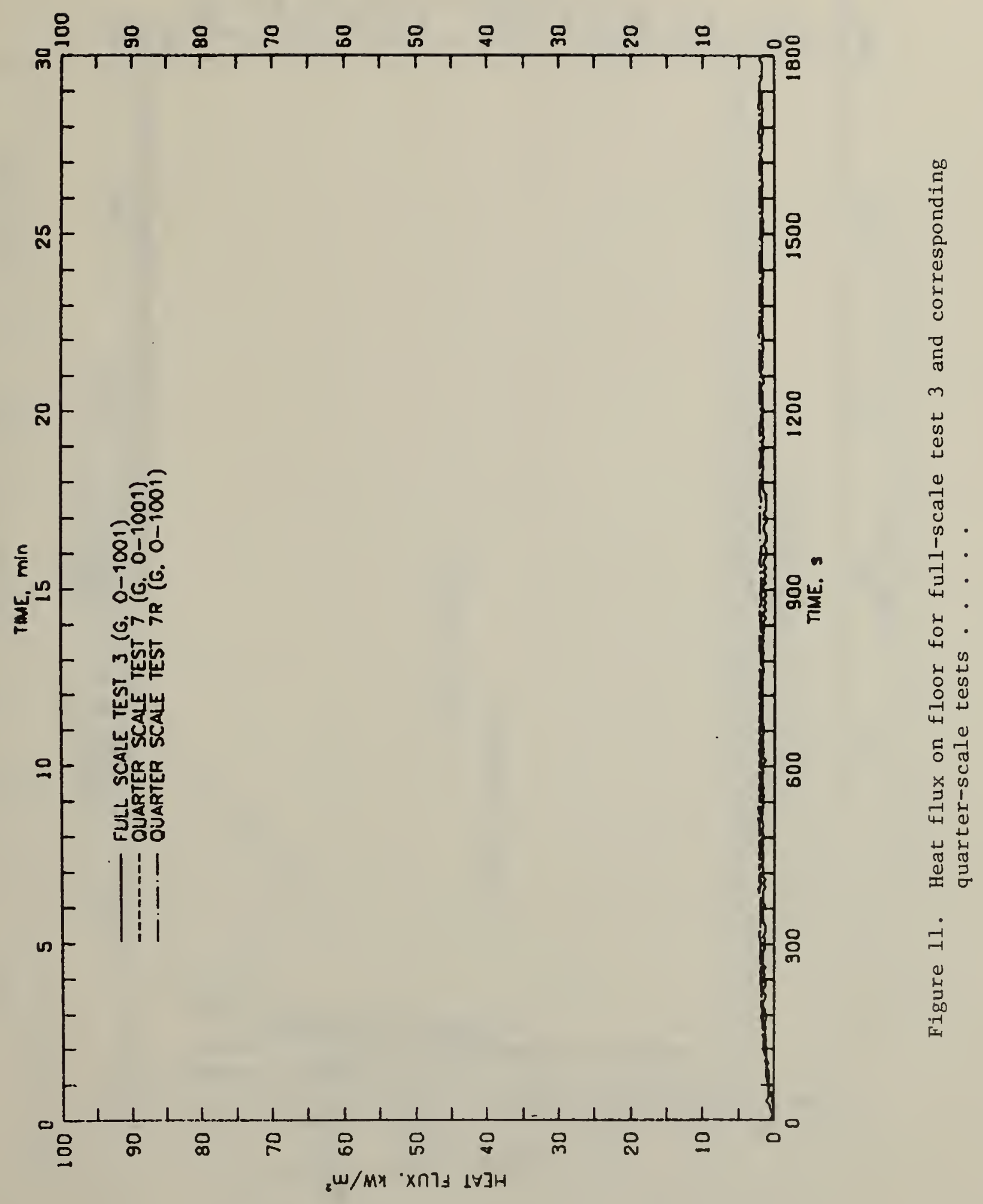




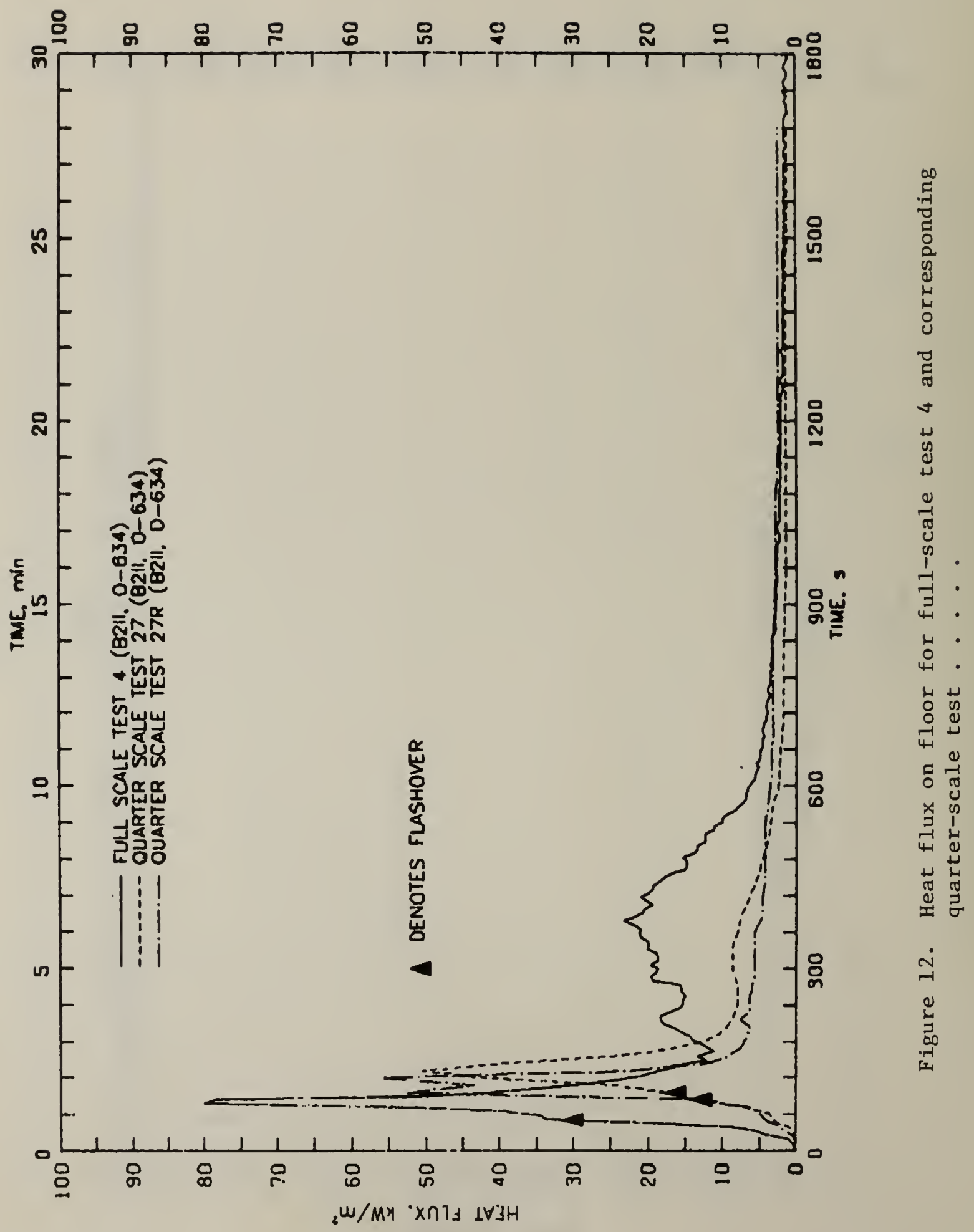




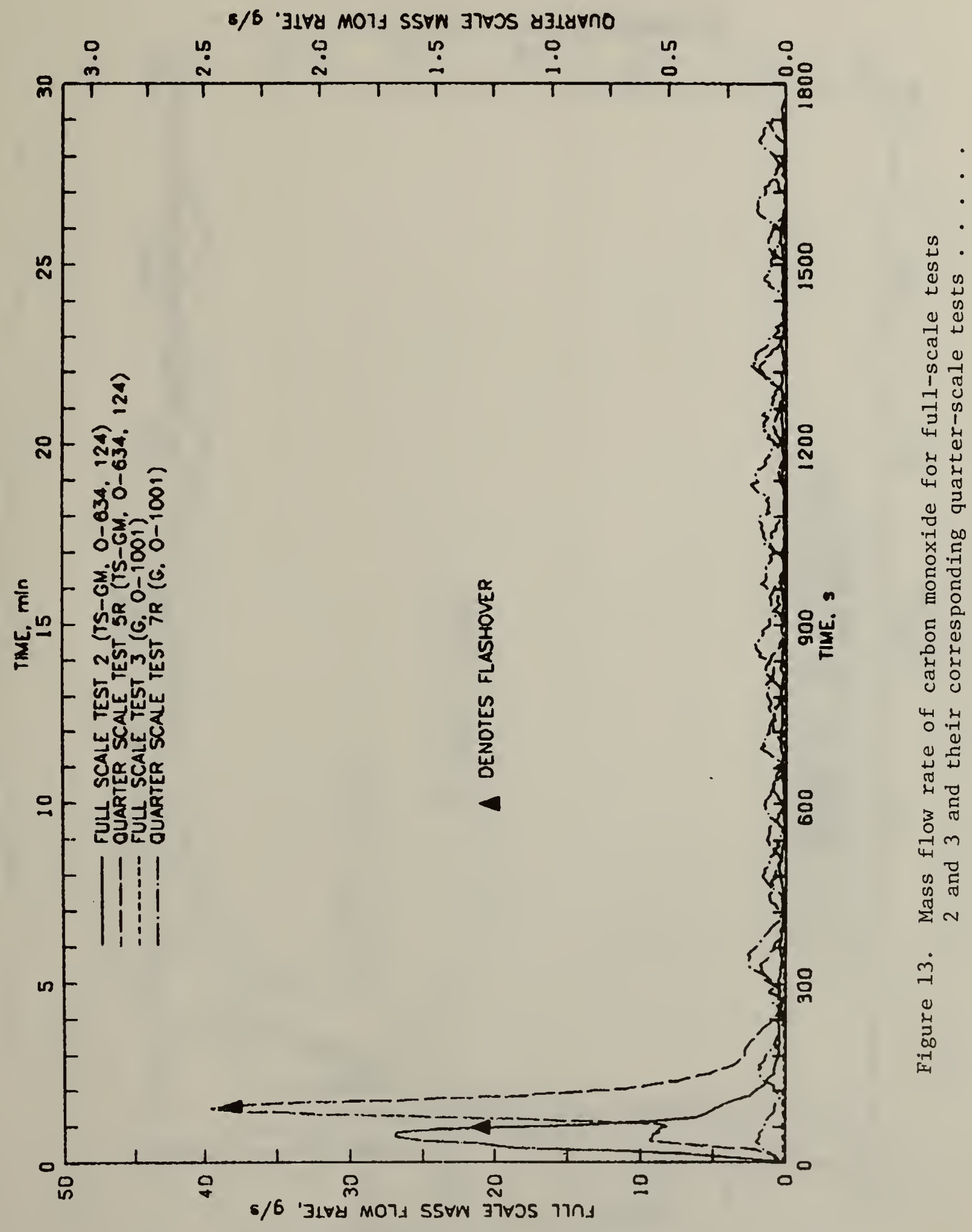




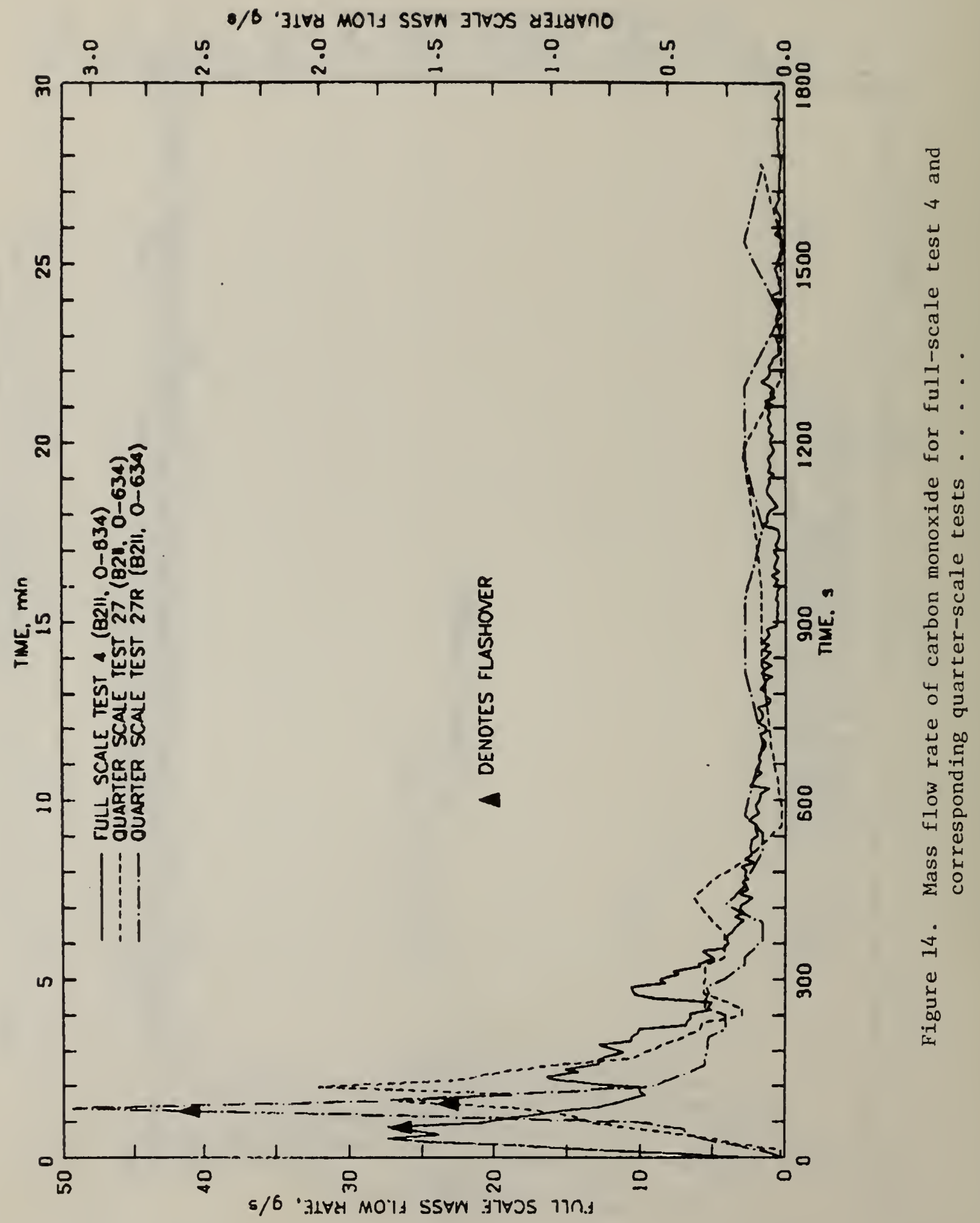




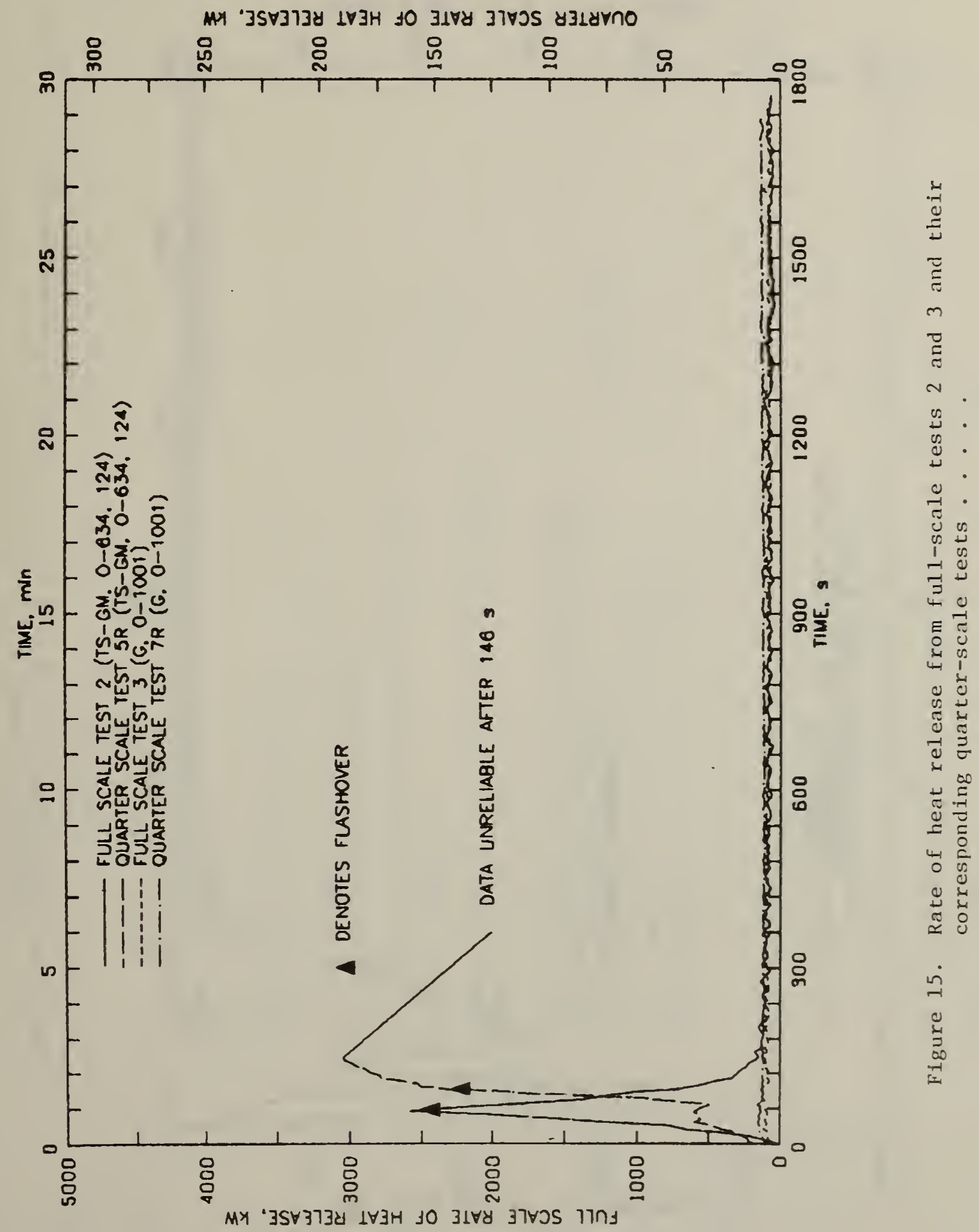




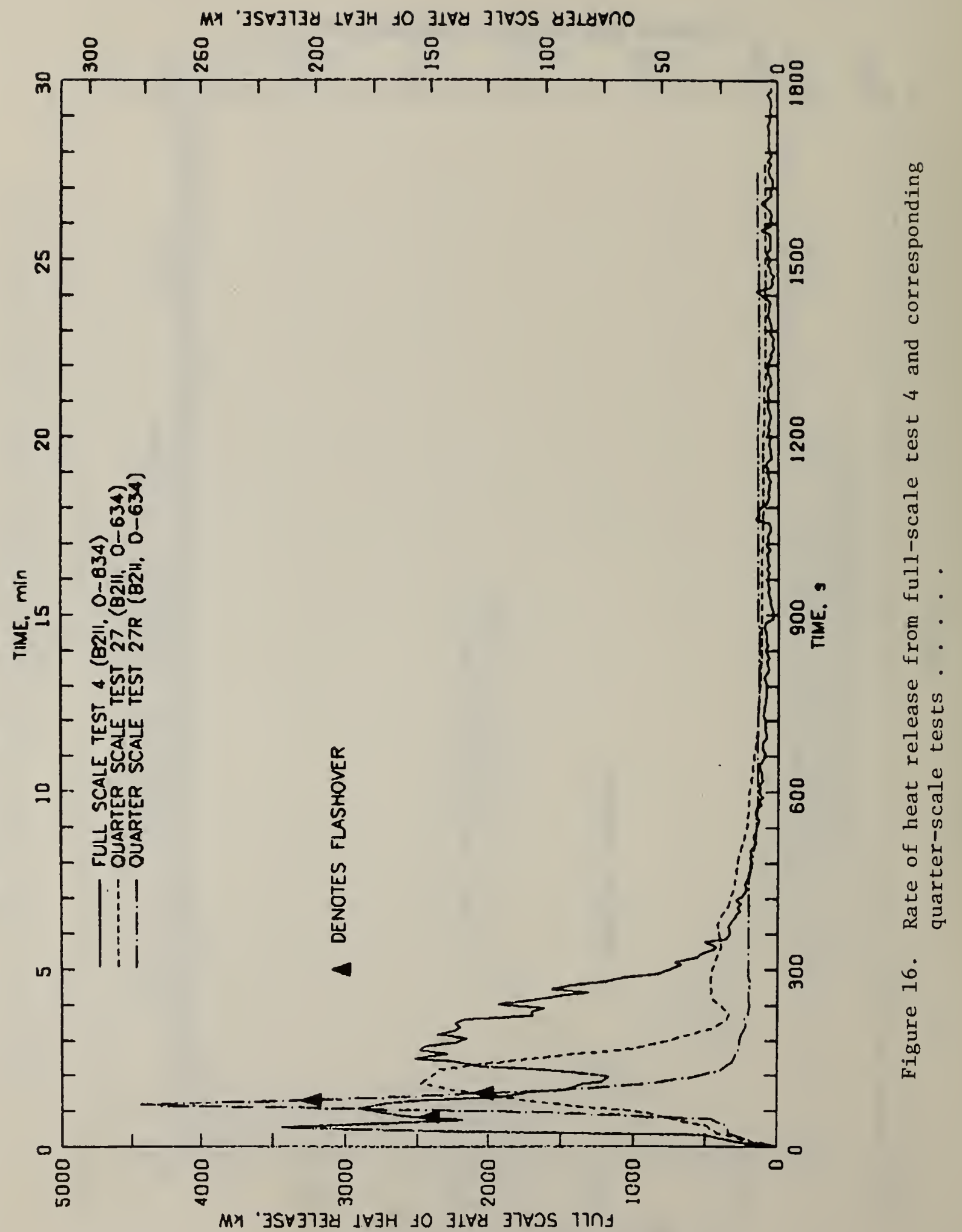




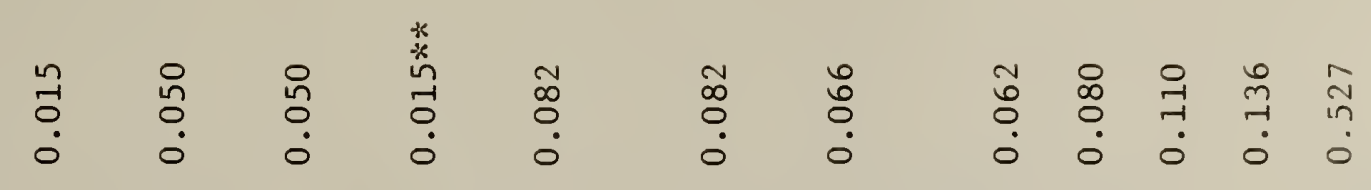

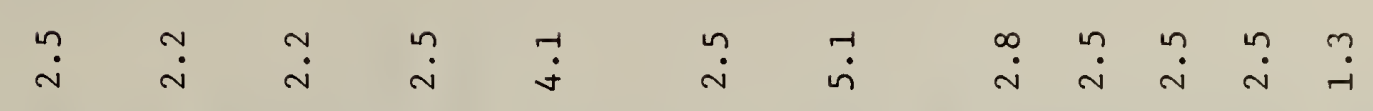

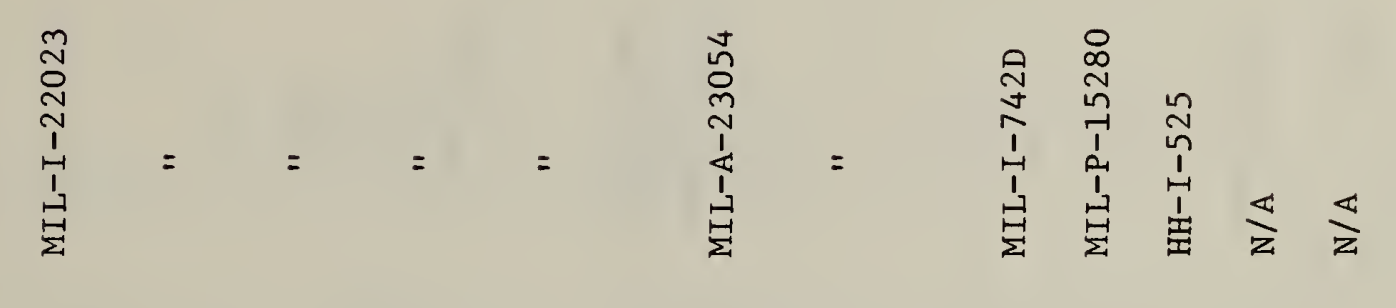

1

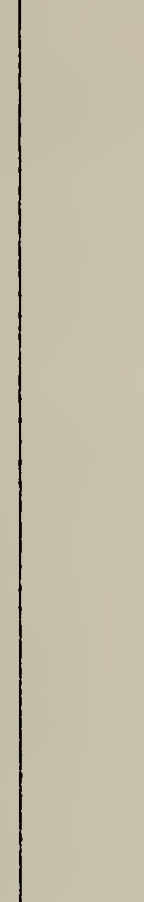

$\underset{\substack{n \\ 0}}{0}$

تี

E్

$\stackrel{0}{\perp}$

$\stackrel{7}{*}$

o

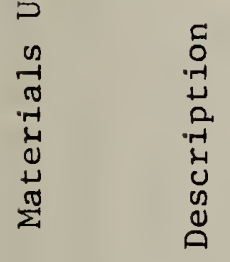

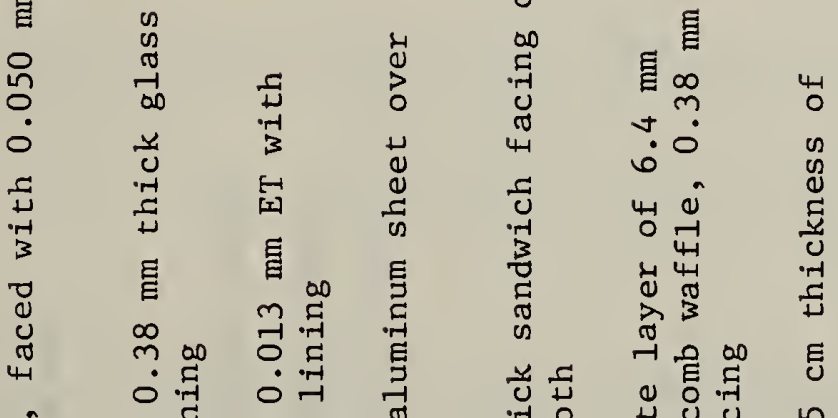

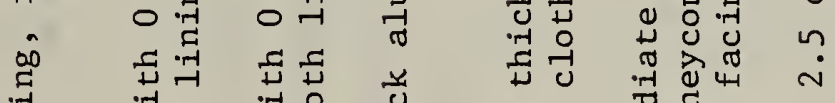

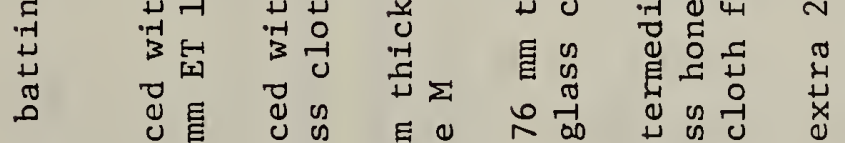

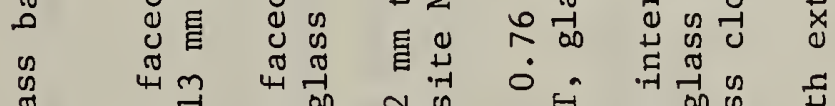

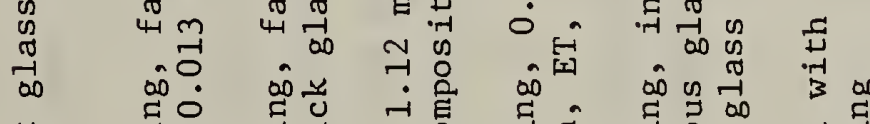

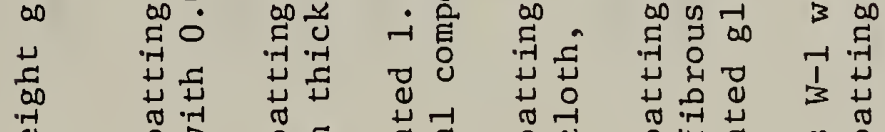

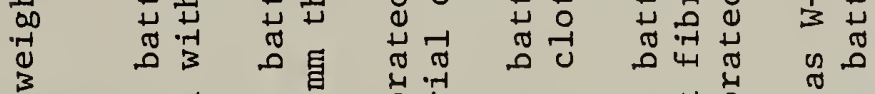

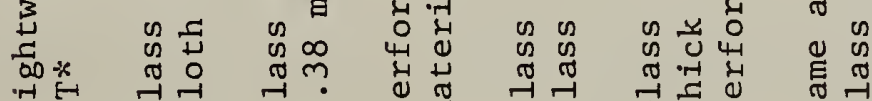

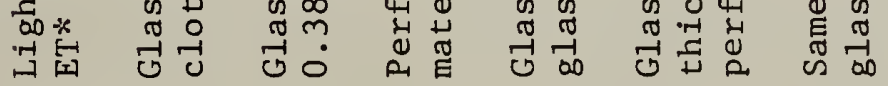

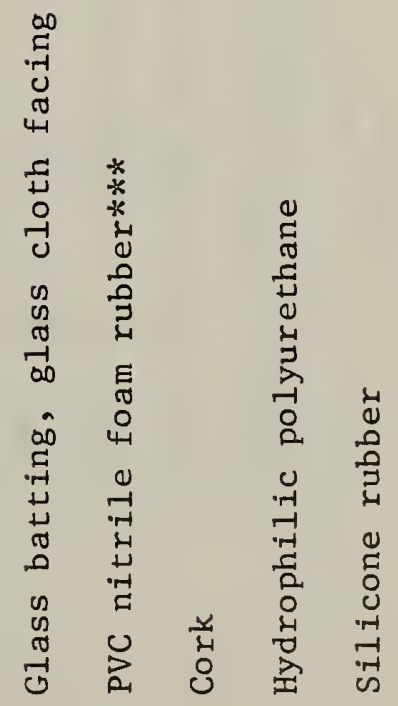

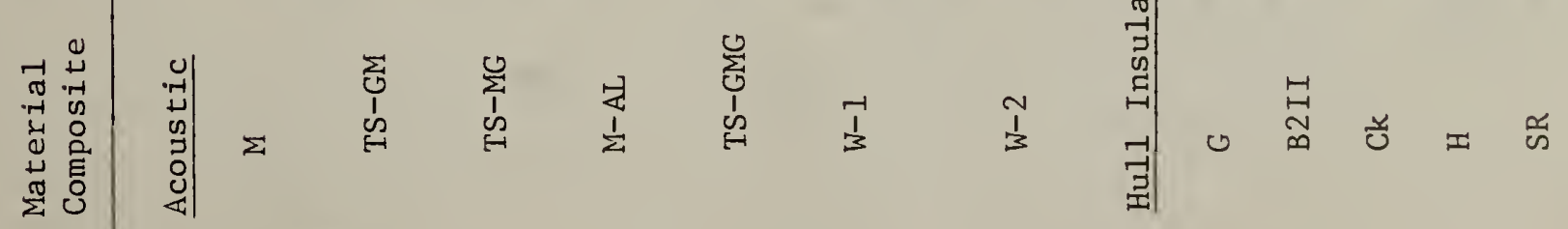


Table 2. Comparioon of Rasults from Full-Scsle Room Fire Tasts snd thelr Counterpart Quarter-Scale Teats+

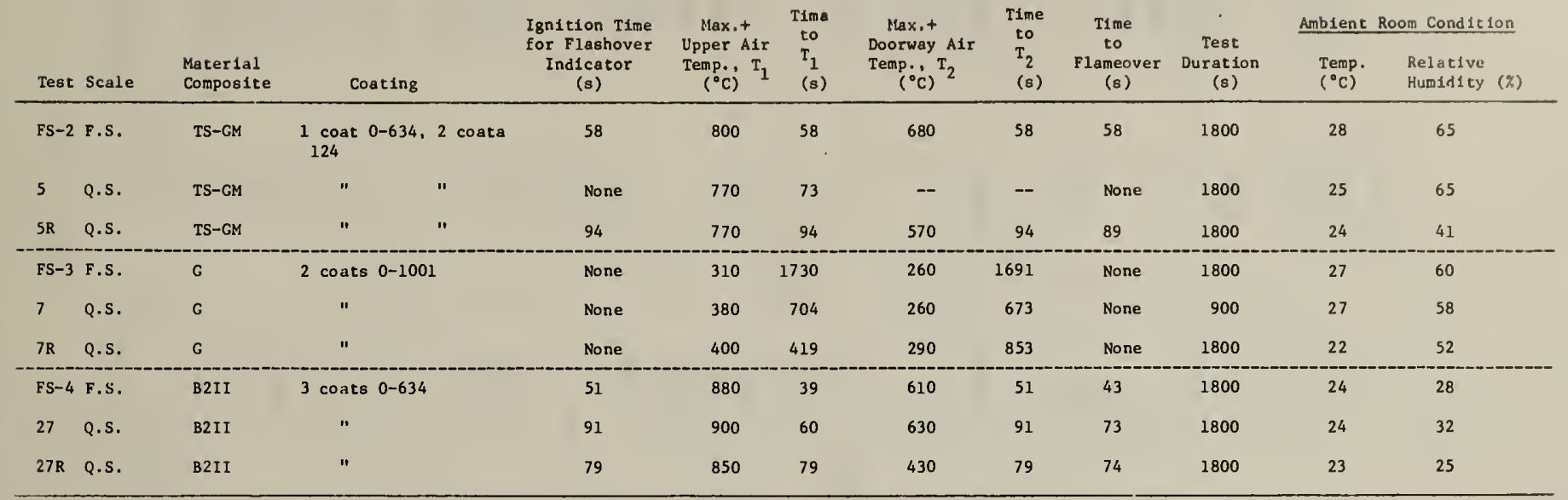

\begin{tabular}{|c|c|c|c|c|c|c|c|c|c|c|}
\hline Test & Scale & $\begin{array}{l}\text { Material } \\
\text { Composite }\end{array}$ & & oating & $\begin{array}{l}\text { Stack Peak Heat+H } \\
\text { Release Rate } Q_{s} \\
(\mathrm{~kW})\end{array}$ & $\begin{array}{c}\text { Time to } \\
Q^{*} \\
(8)\end{array}$ & $\begin{array}{c}\text { Peak CO } \\
\text { in Stack } \\
(\mathrm{g} / \mathrm{s})\end{array}$ & $\begin{array}{l}\text { Time to } \\
\text { Stack co* } \\
\text { (s) }\end{array}$ & $\begin{array}{l}\frac{\text { Peak Smok }}{\text { Conc. }} \\
0 . \text { D./m }\end{array}$ & 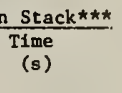 \\
\hline FS-2 & F.S. & TS-GM & $\begin{array}{l}1 \text { coat } \\
124\end{array}$ & $0-634,2$ coats & 2570 & 57 & 27 & 44 & -- & -- \\
\hline 5 & Q.s. & TS-GM & 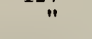 & $"$ & -- & -- & -- & -- & -- & -- \\
\hline $5 R$ & Q.s. & TS-GM & $"$ & $"$ & $76(1216) * *$ & 94 & $2.5(40) \star *$ & * 94 & $>16.4$ & 65 \\
\hline FS-3 & F.S. & G & 2 coats & $80-1001$ & 160 & 68 & $<1.0$ & 347 & -- & -- \\
\hline 7 & Q.s. & G & $"$ & & -- & -- & - & -- & -- & -- \\
\hline $7 ! 3$ & Q.s. & c & $"$ & & 7 (112) & 40 & $<0.2(<3)$ & 349 & 0.7 & 199 \\
\hline FS -4 & F.s. & B2II & 3 coats & s $0-634$ & 3450 & 33 & $2 \%$ & 33 & -- & - \\
\hline 27 & Q.s. & B2II & $"$ & & $131(2096)$ & 91 & $1.5(24)$ & 91 & $>16.4$ & 51 \\
\hline $27 \mathrm{R}$ & Q.s. & B2I I & " & & $277(4432)$ & 79 & $2.6(42)$ & 79 & $>16.4$ & 36 \\
\hline
\end{tabular}

+Peak values of $T_{1}, T_{2}, Q_{8}, C 0$, and $0 . D . / m$ measured at times prior to or at 1gnition of newspaper flashover indicator. $T_{1}$ measured at $25 \mathrm{~mm}$ below ceiling, and $T_{2}$ measured at 25 below doorway for quarter-8cale tests. $T_{1}$ and $T_{2}$ measured at 102 mm for full-scale tests.

Hincludes ignition gas burner rate of heat release of $90 \mathrm{~kW}$ in full-scale test and $5.6 \mathrm{~kW}$ in quarter-scale test.

*Times to peak rate of heat release (baaed on oxygen consumption) and peak co production have been adfusted for the transit times of these gases in the sampling lines.

**Values in parenthesis represent full-scale equivalent values which are 16 times greater than the quarter-scale values.

$\star \star \star$ Smoke attentuation over path length of $152 \mathrm{~mm}$. 


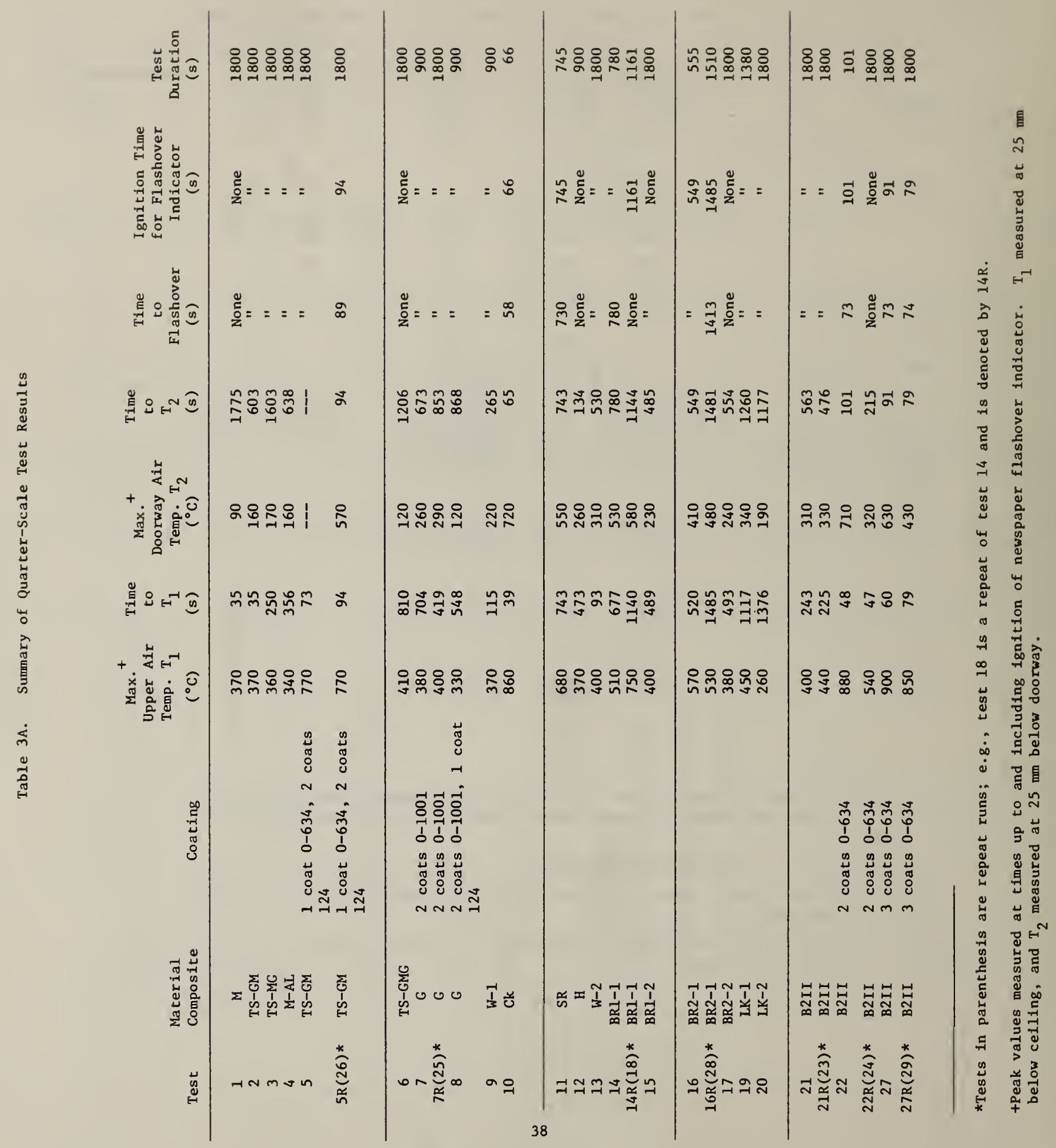




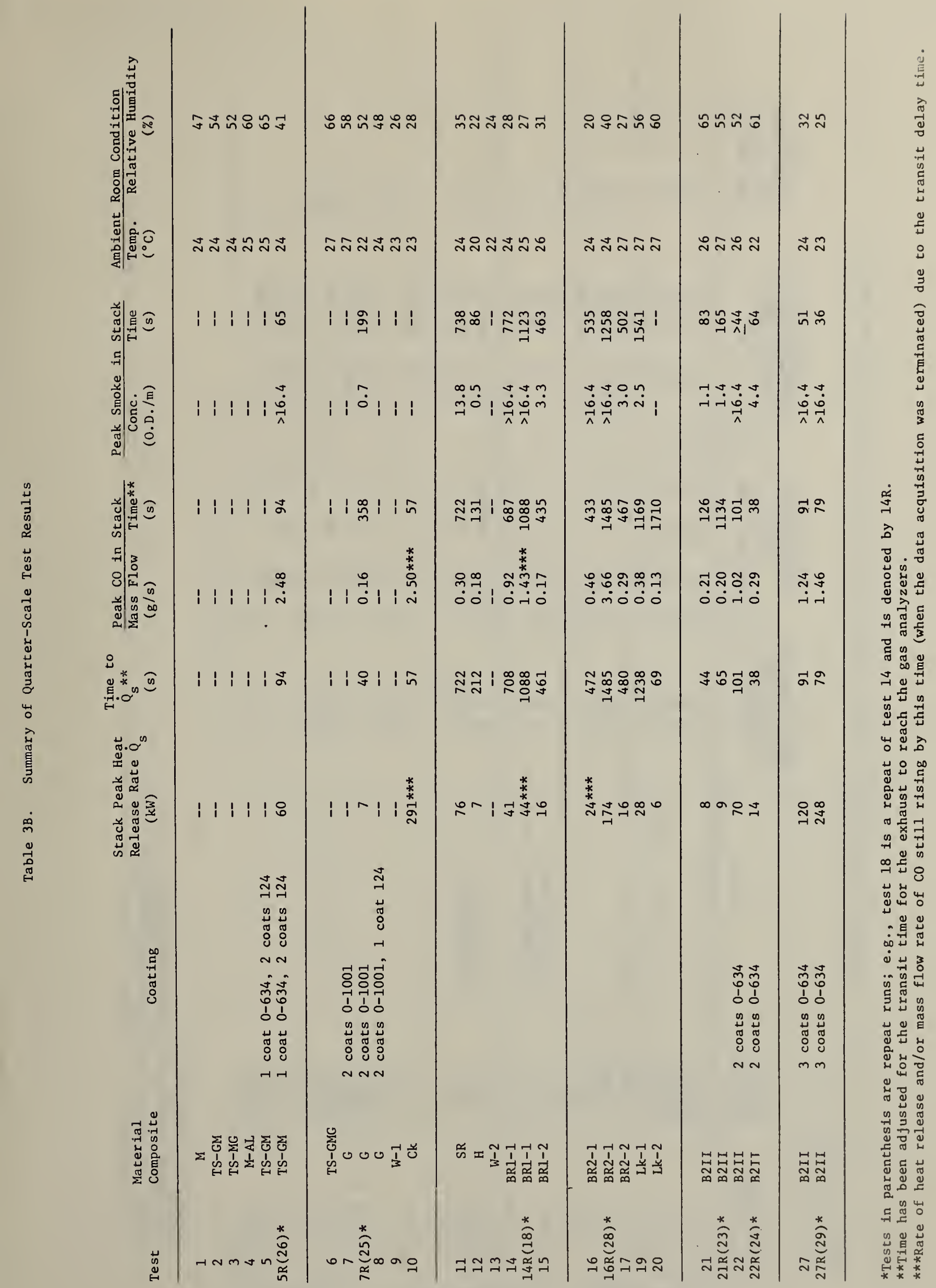




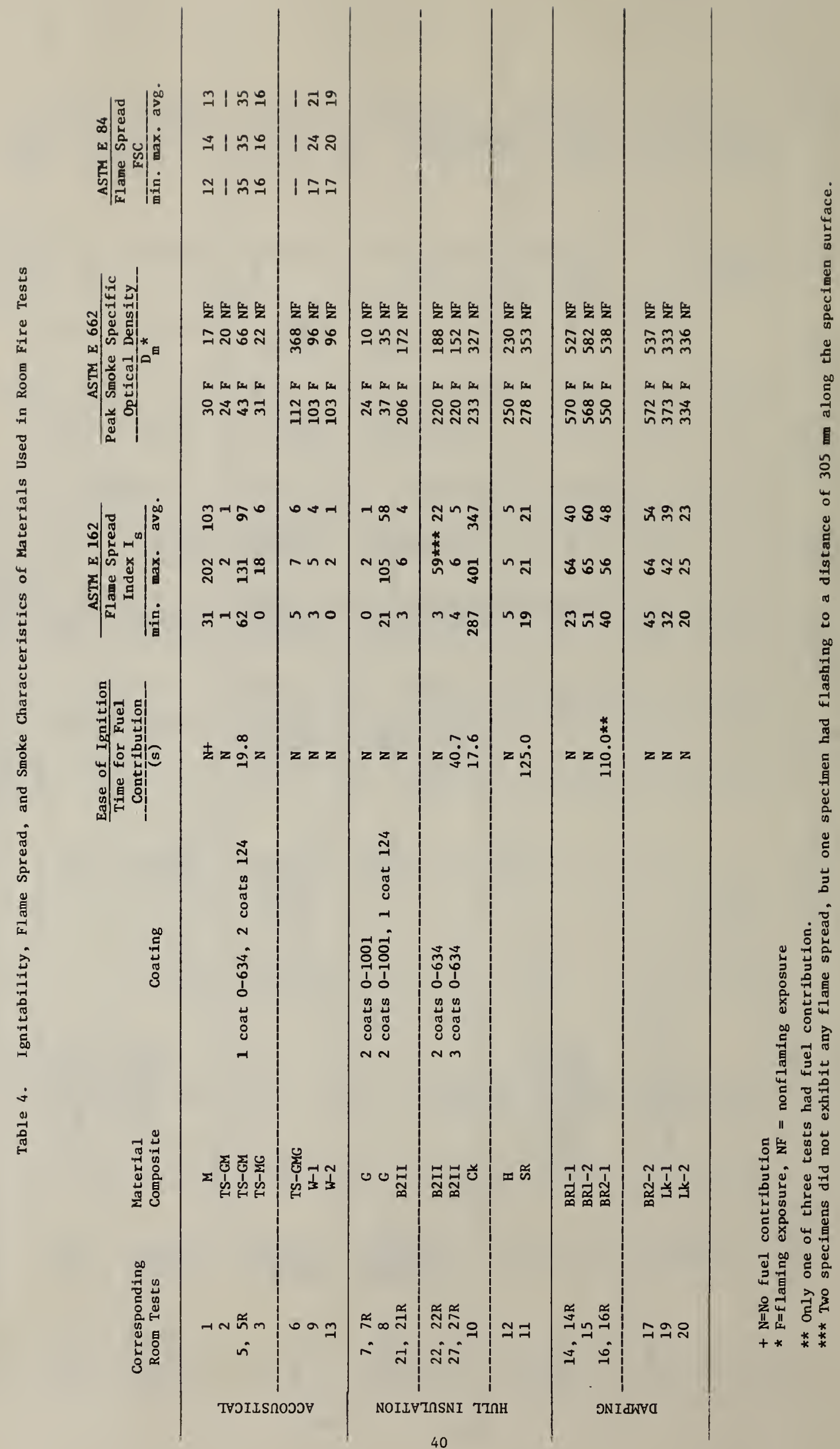




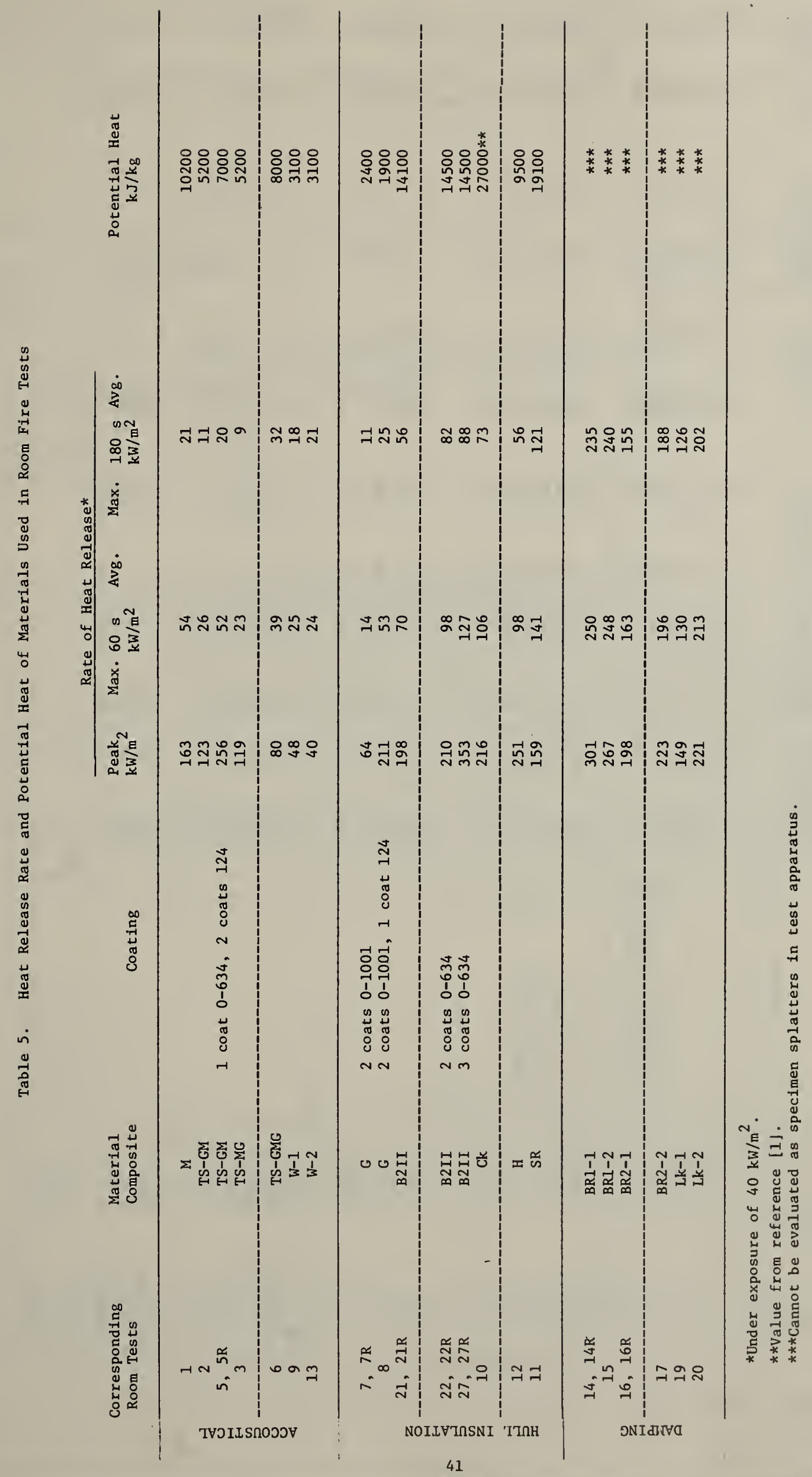




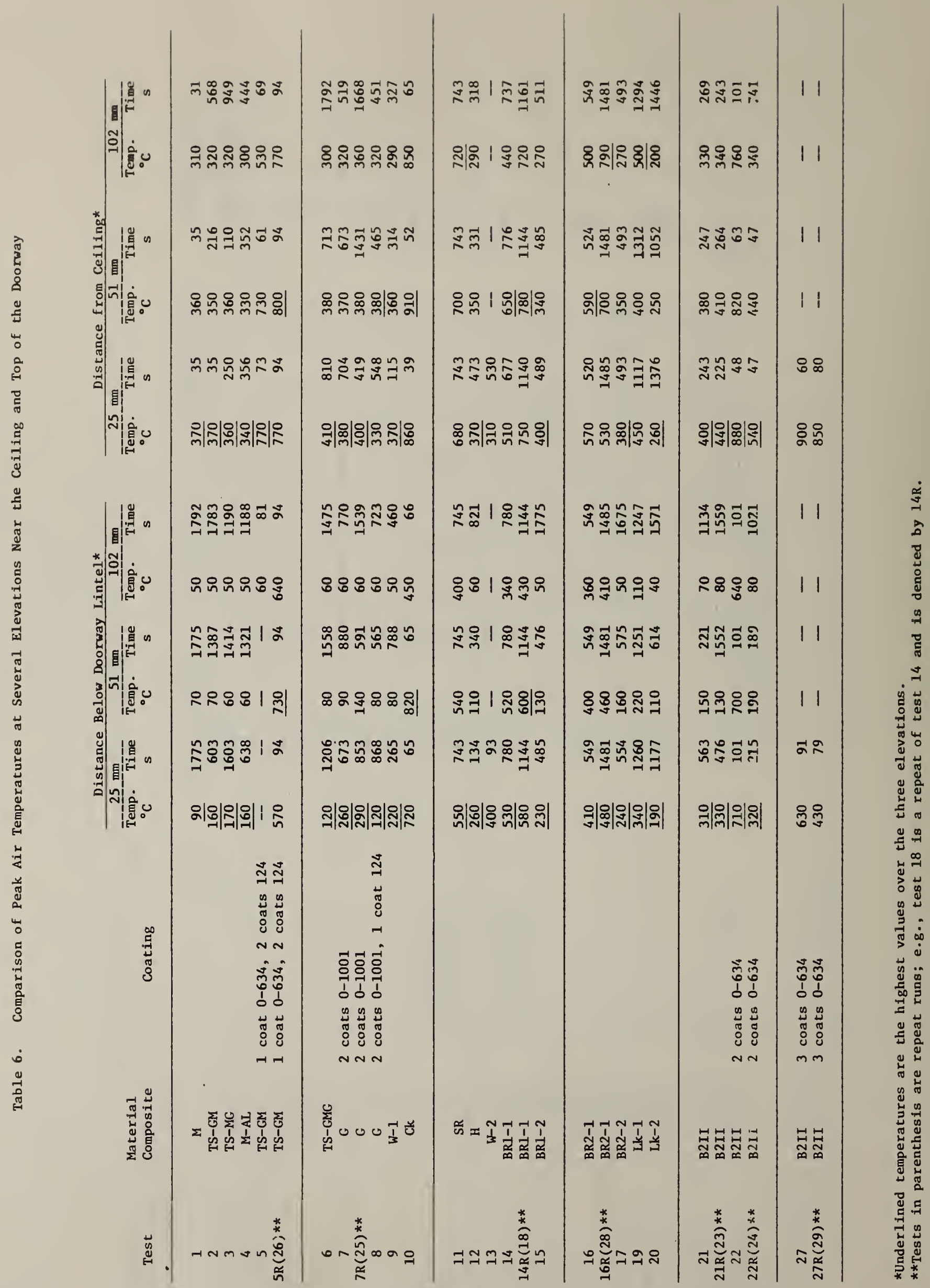


BIBLIOGRAPHIC DATA

4. TITLE AND SUBTITLE

Fire Hazard Evaluation of Shipboard Hull Insulation and Documentation of a Quarter-Scale Room Fire Test Protocol

5. $\operatorname{AUTHOR}(S)$

B. T. Lee

6. PERFORMING ORGANIZATION (If joint or other than NBS, see instructions)

7. Contract/Grant No.

NATIONAL BUREAU OF STANDARDS

DEPARTMENT OF COMMERCE

WASHINGTON, D.C. 20234

9. SPONSORING ORGANIZATION NAME AND COMPLETE ADDRESS (Street, City, Stote, ZIP)

Ship Damage Prevention and Control

Naval Sea Systems Command

Department of the Navy

Washington, D.C. 20362

10. SUPPLEMENTARY NOTES

[Document describes a computer program; SF-185, FIPS Software Summary, is attached.

11. ABSTRACT (A 200-word or less foctual summary of most significant information. If document includes a significant bibliography or literature survey. mention it here)

A variety of shipboard hull insulations including damping and acoustical materials, painted and unpainted, were evaluated for their flashover potential using a quarter-scale room fire test developed by the Center for Fire Research at the National Bureau of Standards. Three painted insulations were also evaluated in full-scale room fire tests. Comparison of full-scale and quarter-scale fire behavior again demonstrated that the quarter-scale test can predict full-scale room fire buildup. It was found that decorative paints, including the Navy's chlorinated alkyd formulation, could seriously compromise the fire safety of otherwise low fire risk insulations. A recommended test protocol was developed for determining the flashover potential of hull insulation using the quarter-scale room fire test.

12. KEY WORDS (Six to tweive entries; alphabetical order; capitalize only proper names; and separate key words by semicolons) flammability; flashover; heat release rate; insulation; interior finishes; paints; room fires; ships; sma11-scale fire tests

13. AVAILABILITY

XX] Unlimited

$\square$ For Official Distribution. Do Not Release to NTIS

$\square$ Order From Superintendent of Documents, U.S. Government Printing Office, Washington, D.C. 20402.

XX Order From National Technical Information Service (NTIS), Springfield, VA. 22161

14. NO. OF PRINTED PAGES

\section{7}

15. Price 


